

\title{
(Costing) Knowledge-Based Cost Modelling of Composite Wing Structures
}

Wim Verhagen, Pablo Bermell-Garcia, Pierre Mariot, Jean-Pierre Cotton, Domingo Ruiz, Romaric Redon, Ricky Curran

\section{To cite this version:}

Wim Verhagen, Pablo Bermell-Garcia, Pierre Mariot, Jean-Pierre Cotton, Domingo Ruiz, et al.. (Costing) Knowledge-Based Cost Modelling of Composite Wing Structures. International Journal of Computer Integrated Manufacturing, 2010, pp.1. 10.1080/0951192X.2010.531292 . hal-00649053

\section{HAL Id: hal-00649053 https://hal.science/hal-00649053}

Submitted on 7 Dec 2011

HAL is a multi-disciplinary open access archive for the deposit and dissemination of scientific research documents, whether they are published or not. The documents may come from teaching and research institutions in France or abroad, or from public or private research centers.
L'archive ouverte pluridisciplinaire HAL, est destinée au dépôt et à la diffusion de documents scientifiques de niveau recherche, publiés ou non, émanant des établissements d'enseignement et de recherche français ou étrangers, des laboratoires publics ou privés. 


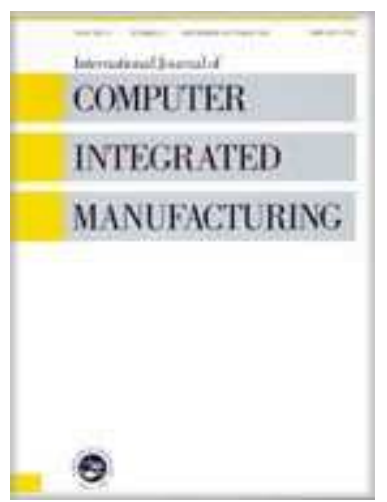

\section{(Costing) Knowledge-Based Cost Modelling of Composite Wing Structures}

\begin{tabular}{|c|c|}
\hline Journal: & International Journal of Computer Integrated Manufacturing \\
\hline Manuscript ID: & TCIM-2010-IJCIM-0124 \\
\hline Manuscript Type: & Special Issue Paper \\
\hline $\begin{array}{r}\text { Date Submitted by the } \\
\text { Author: }\end{array}$ & 25-Aug-2010 \\
\hline Complete List of Authors: & $\begin{array}{l}\text { Verhagen, Wim; Delft University of Technology, Faculty of } \\
\text { Aerospace Engineering, Air Transport \& Operations } \\
\text { Bermell-Garcia, Pablo; EADS Innovation Works, TCC5 } \\
\text { Mariot, Pierre; Ardans SAS } \\
\text { Cotton, Jean-Pierre; Ardans SAS } \\
\text { Ruiz, Domingo; EADS Innovation Works, TCC3 } \\
\text { Redon, Romaric; EADS Innovation Works, TCC5 } \\
\text { Curran, Ricky }\end{array}$ \\
\hline Keywords: & COMPOSITE MATERIALS, COSTING \\
\hline Keywords (user): & Engineering Knowledge Management \\
\hline
\end{tabular}

\section{SCHOLARONE" Manuscripts}




\title{
Knowledge-Based Cost Modelling of Composite Wing Structures
}

\author{
Wim J.C. Verhagen ${ }^{\mathrm{a}, 1}$, Pablo Bermell Garcia ${ }^{\mathrm{b}}$, Pierre Mariot ${ }^{\mathrm{c}}$, Jean-Pierre \\ Cotton $^{\mathrm{c}}$, Domingo Ruiz ${ }^{\mathrm{b}}$, Romaric Redon ${ }^{\mathrm{d}}$, Richard Curran ${ }^{\mathrm{a}}$
}

${ }^{a}$ Department of Air Transport \& Operations, Faculty of Aerospace Engineering, Delft University of Technology, Delft, The Netherlands; ${ }^{b}$ EADS InnovationWorks UK, Bristol, $U K ;{ }^{c}$ Ardans SAS, Paris, France; ${ }^{d}$ EADS InnovationWorks, Toulouse, France

\begin{abstract}
The progressive industrialization of composite-built aircraft is putting manufacturing engineers on a steep learning curve. An opportunity exists to use knowledge management tools to capture, share and reuse knowledge over multiple aircraft programs and maintain the constant flow of learning gained during aircraft program delivery. This paper reports on research to develop a knowledge-based cost modelling capability for composite part concept evaluation. The approach integrates a knowledge management environment with a processbased cost estimation tool encoded in very large spreadsheets. In order to achieve this, the complexity of the cost model is managed by modularizing it into simple, re-useable components. The knowledge management environment is then used to manage the knowledge lifecycle, knowledge exploitation and knowledge visibility of those components. The result is a flexible cost modeling tool composed of traceable, verifiable and reliable knowledge elements that provides through-life knowledge support for cost engineering. Validation is achieved through functional application of the solution for composite wing top cover cost modelling.
\end{abstract}

Keywords: engineering knowledge management; knowledge engineering; cost modelling; composites

\section{$1 \quad$ Introduction}

A recent challenge in aerospace engineering is the trend to switch from predominantly aluminium to predominantly composite structures, as evidenced by the development of the Boeing B787 and the Airbus A350 XWB (Extra Wide Body). From the manufacturing perspective, this is a major step change since it imposes the need to create and update existing knowledge bases to adapt industry to this new demand. The UK government has recognized this issue in its national Technology Program. Consequently, a series of research initiatives are being funded to build the necessary industrial foundations and knowledge to face the composite manufacturing challenge (Airbus, 2010, Technology Strategy Board, 2009).

\footnotetext{
${ }^{1}$ Corresponding Author. E-mail: w.j.c.verhagen@tudelft.nl
} 


\section{W.J.C. Verhagen et al.}

Competitive pressure is forcing manufacturers to adapt quickly in order to industrialize the use of composites in aircraft design. To successfully face the associated learning curve, manufacturing engineers will need to be supported while encountering composite manufacturing challenges in their daily practice. In this scenario, fast and accurate access to up-to-date knowledge in early-stage design will be crucial to accomplish program objectives while avoiding the undesirable effects of producing composite-made aircraft while having used metal design and analysis principles.

This paper presents an innovative approach to manage manufacturing engineering knowledge through life in the domain of cost modelling for composite components. The underlying research objectives are to illustrate the principles that have guided the development effort and to validate the solution by presenting a functional integration of a knowledge management environment and a real-life, operational cost modelling tool. The developed solution supports cost evaluation of product concepts at early stages of the design process while offering the opportunity for through-life knowledge support. A key aspect of this research is the adoption of the following Knowledge Management (KM) principles in the development of the solution:

- Exploitation of the knowledge: The primary aim of the resulting KM capability is to be able to "run" cost models using trustworthy and up-to-date knowledge. The transformation of tacit knowledge into explicit knowledge is secondary but is also supported.

- Visibility of the knowledge: The KM capability is designed to improve upon the current black-box implementation of the cost modelling capability. To achieve 
this, the solution does not replace the natural use of spreadsheets to compute the cost of components. However, it manages the knowledge driving the cost model and deploys it to a working spreadsheet from which users can understand the rationale of the computed cost.

- Lifecycle management of the knowledge: The KM capability enables taking diverse paths to evolve the cost model. However, it also enables control of the actual standard way of costing parts. Furthermore, it enables storing, justifying and updating cost model knowledge elements and records previous versions of the cost model.

This short introduction of the research problem, objectives and solution elements is substantiated in the remainder of the paper. First, the research background is evaluated. This includes a brief assessment of relevant theoretical aspects, which is followed by a more involved description of the research problem in terms of managing engineering knowledge and associated elements. Subsequently, an explorative case study is performed which analyses cost modelling of aerospace composite components through life. The research problem and the case study elements are combined to lead to a knowledge-based framework for managing cost models through life, which is discussed in Section 4. First, semantic unification of the cost model elements and knowledge base structure is achieved. Next, the framework principles and architecture are proposed. Finally, a proof of concept application is described which illustrates the functional implementation of the framework principles and architecture. This proof of concept serves as an initial validation of the knowledge-based cost modelling approach. A final discussion with conclusions and limitations wraps up the paper. 


\section{W.J.C. Verhagen et al.}

\section{Research background}

In this Section, literature is reviewed to establish the context of the research. First, current approaches to cost estimation are categorized, which allows the cost modelling approach used in this paper to be placed into context. Subsequently, the concept of knowledge is briefly explored, followed by its application in engineering knowledge management. Next, three major KM principles are explored. This serves to show which elements in $\mathrm{KM}$ are currently insufficiently addressed in theory and practice, and thereby guides the approach for the case study and the solution framework.

\subsection{Categorization of current approaches to cost estimation}

A number of authors discuss and categorize current approaches to cost estimation. The most universally adopted perspective on cost modelling (Feldman \& Shtub, 2006, Newnes et al., 2008, Curran et al., 2004, Price et al., 2006) refers to three approaches, namely analogous, parametric and bottom-up cost modelling. Curran et al. (2004) present a matrix of comparative assessment for these methods, which is given here in Table 1. It is important to note here that one of the subsets of bottom-up modelling is physical process modelling, which focuses on the time required to carry out work (Curran et al., 2004) as this principle is used in the cost modelling approach outlined in this paper (see Sections 3.1 and 4.1.1).

Table 1: Assessment matrix for traditional cost estimation methods (Curran et al., 2004)

Curran et al. (2004) also distinguish between 'traditional' and 'advanced' estimating approaches. The three approaches mentioned in Table 1 are deemed to be traditional, whereas advanced estimating approaches include the use of feature-based 
modelling, fuzzy logic, neural networks, uncertainty modelling, and data mining. Curran et al. (2004) also introduce the genetic causal cost model to address the need for a more scientifically based methodology for cost estimation.

Newnes et al. (2008) add a more upper-level categorization perspective by considering cost estimation approaches as being 'generative' or 'parametric'. In the generative process, the cost estimation builds upon the data that is gathered during the design process. Consequently, the costing estimate accuracy depends on the level of data detail. In parametric approaches, estimates are 'achieved based on past experience, using findings from past products and estimating the expected cost' (Newnes et al., 2008). Parametric approaches distinguish themselves by the use of cost-estimating relationships (CER).

Newnes et al.'s (2008) categorization relates closely to the level of fidelity of the cost estimation approaches; as Price et al. (2006) indicate, 'analysis fidelity relates to the degree of detail and accuracy contained in a given analysis model'. Price et al. (2006) distinguish three levels of fidelity. Low fidelity models use simple equations and look-up tables, and frequently do not have associations with geometric models. Medium fidelity models use some form of linear analysis in combination with geometric model information and high fidelity models contain a lot of detail while modelling non-linear behaviour. When looking at the issue of fidelity from a more multidisciplinary perspective, a number of research gaps can be identified (adapted from Price et al., 2006) - see Table 2.

Table 2: Disciplines versus fidelity (modified from Price et al., 2006) 


\section{W.J.C. Verhagen et al.}

It is interesting to note that significant gaps exist for the cost discipline (at the medium to high fidelity levels) and manufacturing (at the low to medium fidelity levels). This conclusion will be revisited when inspecting the cost modelling approach outlined in this paper (see Section 3.1).

\subsection{Engineering knowledge management}

Nonaka (1994) defines knowledge as 'a justified belief that increases an entity's capacity for effective action'. Alavi and Leidner (2001) offer a deep and involved literature review on the concept of knowledge; in particular, their main conclusions are that 1) literature focuses heavily on distinguishing between data, information and knowledge, 2) knowledge is personalized and should therefore be expressed in such a manner that it is interpretable to receivers, and 3) only information that is actively processed in the mind of an individual or individual(s) is useful. These realisations are carried through in this paper; in its applied form (see Sections 3 and 4) 'knowledge' covers the engineering domain and encompasses parameters and their values as well as formulas (together constituting data and information), as well as the justification for these parameters and formulas (constituting the conventional 'knowledge' as used in literature). Furthermore, the realisations that knowledge must be interpretable to receivers and must be processed by users to have an impact are guiding the solution development effort (Section 4).

This solution effort focuses on the application of knowledge management to support an engineering task. Knowledge management can be defined as 'a systemic, organized, explicit and deliberate ongoing process of creating, disseminating, applying, renewing and updating the knowledge for achieving organizational objectives' (AmmarKhodja and Bernard, 2008). Knowledge management helps organizations in various 
ways, such as retaining knowledge after loss of key staff and ensuring effective use of structured knowledge, which enables quicker identification, retrieval and leverage of existing company knowledge (Alavi and Leidner, 2001).

For the engineering domain, the need to effectively use structured knowledge to improve engineering work has attracted considerable research effort in the last decades (Oldham et al., 1999, Stokes, 2001, Curran et al., 2010). For instance, the MOKA project (Methodology and tools Oriented to Knowledge-Based engineering Applications) (Oldham et al., 1999, Stokes, 2001) has been a key research effort focused in applying Knowledge Engineering principles in the engineering design domain. It focused on the conversion of tacit knowledge to explicit knowledge through the application of informal and formal models. However, it has become apparent that having an approach to make knowledge explicit is a necessary but insufficient condition to support knowledge intensive work. Siemieniuch and Sinclair (1999) asserted that knowledge - in a manufacturing context - has a lifecycle that needs to be managed. More recently, this issue has been recognised and addressed by the engineering design research community with the aim of capitalising engineering knowledge and information in the long term. Examples of research initiatives in this field are the UK-based project "Knowledge and Information Management Through Life", (McMahon et al., 2005) and the Manufacturing Interoperability programme from the US National Institute for Standards and Technology (NIST, 2007). From a research perspective, the challenge is not anymore on producing working knowledge management capabilities but primarily on making them resilient to changing knowledge and capable to support the multidisciplinary learning process through-life. 
W.J.C. Verhagen et al.

\subsection{Managing engineering knowledge: exploitation, visibility and lifecycle}

The previous discussion indicated a number of aspects that together constitute the fundamental elements of the research problem from a theoretical perspective. First of all, the research challenge is on producing knowledge management capabilities that support the use of dynamic, evolving knowledge through-life. Furthermore, the knowledge contained in such capabilities must be interpretable to receivers and must be processed by users to have an impact. These elements are further addressed in this subsection under the notional headings of the operational exploitation of knowledge, the visibility of knowledge, and the knowledge life-cycle.

Historically, the exploitation of knowledge was at the forefront in the development of knowledge-based systems. Exploitation of knowledge often simply meant that organizational knowledge was incorporated into a KM application; more recently, there is an increasing recognition of the fact that $\mathrm{KM}$ applications should put any required knowledge as close as possible to the operational needs of the user (Mariot et al., 2007b). The operational exploitation of knowledge must be sufficiently addressed in knowledge management capabilities. As Redon et al. (2007) note, 'the exploitation of Knowledge Management within an engineering context ... is about providing the right information [sic] to the engineer, at the right time, in the right format, in a collaborative environment that promotes learning within the organization'. When a user is in a given context the business tool must include the relevant knowledge in this context. Moreover, this knowledge must support decision making and can sometimes even partially automate decision making. If implemented otherwise, knowledge remains in a separate application which can be subsequently be typified as black-box (Kulon et al., 2006, Choi et al., 
2007). Users will not optimally (if at all) acquire and use this knowledge in their daily practice; the visibility of knowledge will be too low.

The required visibility of knowledge enabled through KM is only achieved if users accept the knowledge management solution. As mentioned before, this is complicated in practice as many knowledge-based applications are perceived as 'blackbox' applications: in short, the user does not know what is going on inside the application and has to rely on the results. A survey by Bermell Garcia \& Fan (2008) indicated that one of the most important business functions to be supported by knowledge-based engineering systems is to 'increase the transparency of KBE application functionalities and data processing'. Another critical aspect in achieving visibility is that users have to be involved in knowledge updating. Again, this observation is supported by Bermell Garcia \& Fan, as 'the increase of efficiency in maintaining and updating KBE applications' is ranked second on importance for support. Knowledge updating and maintenance is obtained only if knowledge management provides a real added value to users. This is relatively easy to achieve for newcomers but more difficult for already experienced engineers, which is frequently the case at established industrial consortia. For experienced engineers, only knowledge integrated with business applications can bring the required added value. This issue has been recognized for many years, but has not yet been adequately addressed. The aforementioned MOKA project (Stokes, 2001) also tried to solve this issue. MOKA exploited previous research efforts on Knowledge Engineering by the adoption of the CommonKADS methodology and its principles (Schreiber et al., 1999) into the development of engineering knowledge systems. The key point of MOKA with respect to knowledge visibility was to avoid going straight to 


\section{W.J.C. Verhagen et al.}

application coding without providing for representation of knowledge in a human-

readable format, which is vital for user support. In particular, MOKA's informal model is an attempt to provide this representation. However, it has been argued that MOKA provided limited (technological) support to manage the transitions between the informal and formal knowledge views (Preston et al., 2005).

This ties in with the increasing realization in the knowledge research community that knowledge management applications should govern the whole knowledge life-cycle (Bernard and Ammar-Khodja, 2008, Mariot et al., 2007a). The knowledge life-cycle is conventionally interpreted as the continuous, iterative transfer of tacit to explicit knowledge (Nonaka, 1994) and vice versa. The previously mentioned MOKA project (Stokes, 2001) provides well-established methodological support for engineering knowledge acquisition. Although MOKA was not intended to provide a solution for management of the knowledge life-cycle, its methodological approach provides a proper starting point to address the knowledge life-cycle challenge. MOKA aims to support the seamless transition from informal knowledge to formal knowledge through its use of interrelated informal and formal knowledge models. MOKA's informal model consists of ICARE forms: these knowledge forms aim to capture knowledge related to Illustrations, Constraints, Activities, Relationships and Entities. MOKA's formal model consists of an abstract model to represent engineering design information. The roots of this meta-model can be traced down to Function-Behaviour-Structure formalisms developed in the context of Artificial Intelligence in design research (Umeda et al., 1996). There is relatively little research published on the actual use of the MOKA informal model, though some examples are available (e.g. Skarka, 2007). Also, a similar approach has been used to 
represent engineering knowledge in other research initiatives such as the 'Core Product Model' research (Sudarsan et al., 2005). MOKA's methodological approach in its guise of interrelated informal and formal models addresses a key part of the knowledge lifecycle, namely the iterative conversion from tacit to explicit knowledge and vice versa. However, MOKA does not fully address the many nuances of the knowledge life-cycle. For example, an important part in managing the knowledge life-cycle is to ensure full traceability of knowledge and its source(s), as well as the accompanying enrichment process. Also, the traceability argument extends over the design process: throughout this process, concepts are created, trade-offs are performed, and decisions are taken. If the supporting knowledge for this process changes, the impact this has on the design process must be evaluated. Management of the knowledge life-cycle can valuably assist in such an evaluation. Unfortunately, theoretical support for these specific issues in the knowledge life-cycle and practical examples for the implementation of the knowledge life-cycle are limited. In this paper, this research gap will be addressed by covering the life-cycle from an applied perspective.

\section{Costing aerospace composite components through life: a case study}

In this section, a current business approach towards cost modelling of aerospace composite components through life will be studied. It will be shown that the evolution of the cost model and its use in the business process interrelate highly with the fundamental theoretical elements that need to be addressed for knowledge-based applications.

\subsection{Cost model evolution}




\section{W.J.C. Verhagen et al.}

Three fundamental elements of the research problem (knowledge exploitation, visibility and life-cycle) have been identified and put into a theoretical context. In this subsection, a specific business case will be evaluated that shows how these elements also form a challenge from a business perspective.

The business case concerns a bottom-up cost model that has been developed to address current issues on costing concept designs of composite parts and assemblies. In literature, research on cost modelling is rich and varied, both from a general perspective (as discussed in Section 2.1) and from more applied perspectives, for instance throughlife costing (Curran et al., 2003, Curran et al., 2007b, Curran et al., 2008a), manufacturing cost estimation (Curran et al., 2006a, Curran et al., 2008c) and composite material costing (Curran et al., 2008b). Likewise, a number of cost estimation methods and tools using principles established in literature have been developed for business use in aerospace Original Equipment Manufacturers, or OEMs. However, the aforementioned bottom-up cost model is filling a business gap that is not covered by other approaches within the aerospace OEM that cooperated in this research. In fact, the cost model addresses the medium level of fidelity gap that has been identified in section 2.1. Furthermore, its results enable the parameterisation of the costs and times associated with the discrete manufacturing processes for composite parts. Going down to this level of detail in the model enables the generation of discrete event simulations in order to evaluate the initial proposed manufacturing system for meeting a required production rate. In other words, the cost model functionality also acts as an enabler towards lowfidelity estimation for the manufacturing discipline. The cost model evaluation enables the generation of improved manufacturing systems that respond better to the required rate 
under some specific criteria (cost, time, etc.). This results in a revised manufacturing system that meets production requirements against improved performance.

The research problem addressed in this paper emerged from the difficulties of coping with the complexity added to the cost model during its evolution. A snapshot of this process is illustrated in Figure 1.

Figure 1: Cost model evolution

In studying the evolution of the cost model, the following stages from Figure 1 and associated observations are discerned:

- Cost model creation: An initial cost model using manufacturing process aspects that influence the cost of composite wing stringers and panels has been captured within a spreadsheet. The information used is not completely new since some of the parameters and their values come from existing cost estimation data and tools. The resulting spreadsheets not only unveil tacit knowledge but can also be used as a working tool to produce cost and time estimates.

- Cost model growth: The cost model has gained enough relevance and trust among cost engineers, resulting in an expansion of scope. Further developments on the cost model have allowed users to consider costs for various product-process combinations using up to 5 different composite materials / material types. The necessary knowledge has been distributed across spreadsheet tabs. In this growing process, new knowledge has been added to the model. However, existing pieces of knowledge are reused 


\section{W.J.C. Verhagen et al.}

across the material tabs. At this stage, over 400 assumed parameters lie at the basis of the model, augmented with some 30 parameters for which the values are chosen by the user. These parameters drive hundreds if not thousands intermediate calculations, frequently with unique formulas to take into account user configurations, to arrive at process time and cost estimates. The model has become a very complex web of knowledge interactions, in which most knowledge elements have again become tacit in nature as these elements require the explanation of an expert to make sense to outsiders.

- Cost model decomposition: Further enrichment of the cost model (addition of materials, products and processes) has forced its developers to split it down into pieces. At this point, the complexity of the spreadsheet makes it difficult for management and involved use by anyone other than the creators. Other reasons to decompose the model can be found in the need to distribute it to different users responsible for the cost estimation for different composite materials and material types. In this process, some of the knowledge gets classified and distributed to its consumers. However, a significant risk of inconsistency and duplication of the information emerges.

\subsection{Cost model research elements: knowledge exploitation, visibility, and life-cycle.}

Following the analysis of the cost model, it is apparent that the evolution of this cost model has made it very difficult to manage its complexity, as the evolved model consists of many interrelated formulas and inputs that are insufficiently classified. An associated 
drawback is that the inputs used for the model are not maintained on a shared base, but are instantiated for each version of the model: each user has a 'unique' spreadsheet model. If a user makes changes to parameter values to adjust for new knowledge, these changes are not shared with other cost model instances in the business. Knowledge exploitation is a significant problem.

Besides these elements of the industrial problem, the existing cost model has a further number of drawbacks. A significant drawback is the rather inflexible, monolithic nature of the model: the current spreadsheet implementation is focused on certain process-product combinations and does not allow for easy mixing of different materials or sub-processes. A possible route to address this would be to enable the assembly of cost model elements that are stored in a managed environment. Also, the cost model is maintained principally by only two persons, as the complexity of the model precludes more direct governability by the end users (even though the latter can still configure userdefined parameters, variation in the pre-defined parameters and formulas is discouraged). This is of course a business risk, as the full set of required modelling knowledge resides with only two persons in the organization. Both the inflexible nature of the cost model and the lack of more direct governability by the end user provide significant challenges for the exploitation and visibility of knowledge. Also, in its evolved form the cost model can be typified as a 'black-box' application. Because of its complexity and its distribution over multiple spreadsheets and spreadsheet tabs, a user effectively has no other option than to trust the model output. The user must go to considerable lengths to retrieve the original knowledge sources behind the implemented formulas and parameters; the 


\section{W.J.C. Verhagen et al.}

supporting informal knowledge is also very hard to find. Consequently, knowledge visibility is hardly achieved.

Finally, the assumptions, inputs, operations and outputs of the cost model are not managed from a life-cycle perspective. As mentioned, there are currently little to no provisions for explanation of the rationale behind assumptions. Furthermore, the model inputs, operations and outputs change during the lifetime of the cost model, but these changes are not stored, let alone tracked. The enrichment of these knowledge elements during the model life-cycle is not taken into account. This lack of knowledge life-cycle management is a significant stumble block in the learning process towards composite component production and associated cost estimation.

To summarize, three fundamental knowledge management research elements must be addressed from both a theoretical and a business perspective: the knowledge lifecycle, knowledge exploitation and knowledge visibility. The aim of this paper is to present a functional integration of a knowledge management environment and a real-life, operational cost modelling tool. The resulting knowledge-based cost modelling solution will provide both theoretical and practical relevance by addressing the aforementioned fundamental research elements.

\section{A knowledge-based framework to manage cost models through life}

In this Section, a knowledge-based framework to manage cost models through life is posited. The primary aspect of this framework is to tie in the cost model with an underlying knowledge base, which offers the opportunity to manage the model's complexity. Furthermore, it increases operational usability and attractiveness by 
addressing the elements of knowledge life-cycle, exploitation and visibility. The central idea for the framework is to store the cost model knowledge in a managed environment and integrate this managed environment with the spreadsheet application in which the current model is embedded. This allows for assembly of a cost model and its managed evolution (see Figure 2), as opposed to the existing cost model evolution (Figure 1). Figure 2 expresses that the user can access the managed environment and retrieve modularized cost model building blocks to assemble a cost model. If the user changes parameters or functions in the cost model, the resulting changes are highlighted and the costing knowledge base can be manually updated after subjecting the proposed change(s) to configuration management provisions (e.g. user group acceptance of a proposed change).

Figure 2: Managed cost model evolution

To achieve a knowledge-based cost modelling solution, a supporting framework must be developed. This framework uses a number of principles and incorporates a architectural solution proposal. To establish these principles and the architecture, it is necessary to determine the relevant cost model elements. Therefore, a representative part of the cost model will be evaluated. After this, the cost model will be subjected to semantic analysis to constitute a contextual model. This contextual model unifies the semantics necessary for governing the alignment between the cost model and the knowledge management application (see Section 4.3). This unified semantic approach (Section 4.1) is combined with a number of principles leading to the development of a framework architecture (Section 4.2). The framework supports the development of a 


\section{W.J.C. Verhagen et al.}

knowledge-based cost modelling solution, which is tentatively validated in a proof-ofconcept study in Section 4.3.

\subsection{Semantic unification to enable knowledge-based cost modelling}

In this Section, an analysis will be performed on one part of the full cost model focusing on carbon fibre-reinforced plastic (CFRP) wing top cover manufacturing.

\subsubsection{Cost model entities}

The cost model is spreadsheet-based and primarily process-oriented. For a given product with adjustable characteristics, it allows for the flexible estimation of time and cost associated with manufacturing options. The model can be classified as bottom-up, as it uses a physical process modelling approach to estimate costs. The model uses manufacturing processes and underlying sub-processes in combination with relevant manufacturing parameters to arrive at estimates for process times and costs, which are subsequently added to arrive at totals for cost and time. A simple example is shown in Table 3 for some steps in the cost modelling of T-stringer (a stiffening structural member) production, which is part of CFRP wing top cover manufacturing. This example shows the first steps in arriving at process time estimates for the individual sub-processes. First, a set of parameters are derived from geometric models that are coupled with the cost model spreadsheets. These parameters are allocated per detailed process (as given in the left-most column under the 'Calculation' heading). The geometric parameters are then multiplied with or divided by applicable constants or rates, both in baseline (current performance) and target (required performance) forms. This results in time estimates for the individual detailed processes. This is followed by a considerable number of 
calculations to arrive at cost estimates (e.g. through the simple step of multiplication of process times with labour rates) and logistical implementation (e.g. capital outlay). The actual values for the calculation parameters in Table 3 have been excluded for confidentiality reasons. A further important element to note is that the aforementioned detailed process parameters (e.g. 'set time', 'weight', 'slab perimeter') are themselves dependent on a string of calculations that are driven by pre-defined and user-defined parameters, as well as the aforementioned geometric information. By and large, the rates and constants in the right-most 'Calculation' column are based on 'assumed parameters' that almost invariably lack justification of the supporting knowledge.

Table 3: Predefined Manufacturing Process: T-stringer Production - Initial Parameters The previous analysis of the partial cost model can be schematically summarized into a use process with a number of generic elements, as illustrated in Figure 3.

Figure 3: Cost model - Generic Process

When analysing the full cost model, the previously mentioned generic model elements can be generalised and more properly classified. The following basic cost model elements are identified:

- Assumed definitions: These are single values associated to parameters such as machine costs per hour or autoclave times. In some cases, they come from existing cost estimation data and tools. For the rest of the definitions, cost estimators have investigated across experts to identify the best possible assumptions since they are not available in existing models. 


\section{W.J.C. Verhagen et al.}

- User definitions: These are the values that the user of the cost model can modify to drive the cost model. They are usually choices that modify the behaviour of the cost model formulas through the use of "IF-THEN" rules.

- Predefined formulas: These are formulas that use either assumed or user definitions to compute relevant values for each predefined manufacturing process defined in the spreadsheet.

- Predefined manufacturing processes: The manufacturing processes are compositions of formulas and references to assumed and user definitions. Their end results are process time and cost estimates. Their explicit representation on the spreadsheet enables users to easily visualize the range of available processes and their influence on the final cost of the parts.

\subsubsection{Cost model context}

The previously identified basic cost model elements are difficult to introduce into a contextual model as individual parameters and formulas are used multiple times in the cost model. Thus, identification of a context by way of these basic elements may lead towards multiple, disparately used, knowledge elements. This would cause difficulties in the necessary modularization of the cost model (see Section 4.2). For example, using the contextual descriptor 'Number of stringers (N Stringers)' would already lead to five disparate detailed processes in the small example given in Table 3. Therefore, other more suitable semantic cost model concepts are necessary to constitute a contextual model.

Fortunately, the cost model itself has been organised to conform to a very basic classification after its evolution into several decomposed spreadsheets. This 
decomposition was made on the basis of the composite manufacturing technology, which incorporates material type and material processing form: similar models exist for different materials and forms, e.g. CFRP prepreg, CFRP dry fibre or CFRP sandwich. Besides this elementary subdivision, the cost models themselves are organised according to manufacturing breakdown structure and manufacturing processes. The breakdown structure is a hierarchical breakdown of assemblies and products. In the cost model, on a product level similar calculations are performed for different products, for instance the bottom and top covers of the wing box. Furthermore, similar manufacturing processes are employed for parts of these products. For instance, the T-stringer production from Table 3 is used in both bottom and top cover production. An inspection of the full cost model has shown that the basic semantic elements of composite manufacturing technology (a combination of material and form), manufacturing breakdown structure and manufacturing process are sufficient to describe the context of a knowledge element, under the assumption that these contextual elements are developed into more detailed hierarchies for actual use (see Section 4.3). Reassuringly, this categorization conforms to the basic elements utilized for the Genetic Causal costing methodology advanced by Curran et al. (2006b).

These semantic cost model elements form the context dimensions for a top-level contextual description model that can be used to structure knowledge in the knowledge management application (see Section 4). A contextual description model contains the semantics that can be used to specify the context in which the user, application or model operates (Redon et al., 2007). The context dimensions are 'classes or attributes that describe the context' (Redon et al., 2007). As mentioned, the cost model semantic 


\section{W.J.C. Verhagen et al.}

elements are summarized into the contextual model under the top-level headings of composite manufacturing technology, manufacturing breakdown structure and manufacturing process. The overall top-level contextual description model for the cost model, consisting of three primary context dimensions, is given in Figure 4. This contextual model serves as the basis for the hierarchy adopted in the KM application; the three contextual dimensions are the major classes in this hierarchy (see Section 4).

Figure 4: Contextual description model for cost modelling of composite structures

In Section 4.3, the above contextual model will be instantiated for CFRP wing top cover T-stringer production to show how it is used in practice.

\subsection{Framework principles and architecture}

To move towards a successful knowledge-based framework for composite cost modelling that improves upon the current cost modelling approach and answers to the aspects of knowledge exploitation, visibility and life-cycle management, a number of

principles have to be obeyed. These principles are briefly illustrated below. Three distinct steps are identified:

- Modularization \& Classification: the cost model has been modularized to allow for flexible assembly of unique cost models. To achieve this, the existing cost model has been reverse-engineered to define 'building blocks' that describe all the pre-defined inputs, user inputs and model formulas that belong to a sub-process (see also Figures 5 and 6). The use of building blocks in this manner has the desired effect of achieving central management of the inputs and formulas, instead of having multiple 
spreadsheet instances of the cost model. The building blocks are categorized according the previously introduced contextual model. To support this, the context dimensions of composite manufacturing technology, manufacturing breakdown structure and manufacturing process have been developed into hierarchies that offer the necessary classification richness (see Figure 10 in Section 4.3 for an example of this). Using these classification hierarchies allows for unique combinations of knowledge elements in order to find a specific building block.

- Search \& Retrieval: the classifications established in the previous step are used to search for building blocks in the managed knowledge environment. Various search techniques (standard text search, contextsensitive search, etc.) can be used. In the case of context-sensitive searches, multiple consecutive search choices can be made along hierarchical trees to filter down towards the desired end result. The found building blocks can be selected and consequently exported towards the spreadsheet application.

- Cost Model Composition: the building blocks are used to construct an integrated cost model. The proposed solution must be able to manage duplicated knowledge elements when multiple building blocks with similar knowledge inputs are selected and exported. Also, the solution must have the capability of coping with changes in the spreadsheet environment and feeding back these changes into the knowledge base. Of course, this process must be subjected to a validation process: updates in 


\section{W.J.C. Verhagen et al.}

the knowledge base must be shared and agreed upon before acceptance of knowledge base changes.

The solution principles have been used to devise an implementation architecture that is shown in Figure 5.

Figure 5: Implementation architecture

The architecture consists of the following main elements:

- Structured Knowledge Repository: the repository holds a classification of the knowledge elements that are used to compose the cost model building blocks. Each element is represented by a knowledge base instantiation, e.g. into a knowledge article.

- Knowledge Reuse Engine: this architectural element drives the queries that are used to retrieve building blocks from the knowledge base solution. After selection, the building blocks are automatically exported to the spreadsheet environment.

- Knowledge Reuse Spreadsheet: the spreadsheet application retrieves the building blocks and automatically builds the resultant cost model, with all inputs, formulas and outputs in place. The cost model inherits default values from the knowledge base for the user definitions, but these and the other parameters can be changed to suit the user needs. A function is included to compare the cost model elements with the knowledge contained in the knowledge base; if the user makes changes in the open spreadsheet, they can then compare the resulting changes with the original 
values and subsequently choose to update the knowledge base based on the outcome.

An overview of the solution principles and its translation into a functional architecture is shown in Figure 6.

Figure 6: Overview of solution principles (left) and integrated solution (right)

Minor and major evolutions of the cost model (e.g. changes in formulas or changes in building blocks) can be performed by updating the relevant knowledge articles. Through the modularised approach, the changes are automatically incorporated into the building blocks and subsequently into any generated spreadsheet-based cost model.

\subsection{Proof of concept}

To establish the feasibility and validity of the framework, a proof-of-concept solution for knowledge-based composite cost modelling has been developed. This proof-of-concept is illustrated here by introducing the KM application and its use to implement the framework architecture, and by giving an instantiated solution example and the attendant user process.

The KM application of choice for managing the cost knowledge base and its elements is Ardans Knowledge Maker (Mariot et al., 2007a). This application offers a range of options designed to enable user-friendly management of knowledge, for instance through easy categorization and creation of knowledge articles. The application also complies with vital knowledge requirements by focusing on traceability, security and knowledge life-cycle management provision. Traceability and knowledge life-cycle management are achieved through various knowledge article features, including author 


\section{W.J.C. Verhagen et al.}

tracking, tracking of version history, status accounting through user group authorization and article status management. Security provisions include amongst others: password authorization, user rights administration, and knowledge base rights administration. Each knowledge element (e.g. parameter or formula) has been stored into its own AKM knowledge article, which retains the traceability, security and life-cycle management provisions described above. Each knowledge article has the facilities to represent not only the formal knowledge (parameters, formulas), but also the informal and/or tacit knowledge behind the formal knowledge (e.g. rationale for formulas - see Figure 7 for an example knowledge article ${ }^{2}$ ). The knowledge articles are subsequently grouped into specific building blocks. Therefore, one knowledge article can be used in multiple building blocks.

Figure 7: AKM knowledge article example

To illustrate how the knowledge-based cost modelling solution works in practice, an example is presented here that was used as part of a validation exercise at a major aerospace OEM. As presented in Section 4.1.1 previously, the example concerns the production of CFRP T-stringers for a wing top cover, for which the process representation was presented in Table 3. The contextual model described in Section 4.1.2 has been instantiated for this example; the result is shown in Figure 8.

Figure 8: Contextual model - CFRP Wing Top Cover: T-stringer production

\footnotetext{
${ }^{2}$ The knowledge justification has been omitted from this figure for reasons of confidentiality. However, the knowledge article contains the structural elements necessary for explicit knowledge representation.
} 
The contextual dimensions and their associated hierarchies - evidenced in Figure 8 for the product and process dimensions - have been implemented in AKM. These hierarchies can be partially seen in Figure 9.

Figure 9: AKM search environment - hierarchical knowledge representations The user now follows the following process, which is also illustrated in Figure 10. The Figure shows that after opening a spreadsheet-integrated Visual Basic macro (step 1) and calling the AKM environment, the user employs the contextual information displayed in Figure 8 to select the relevant entries in the hierarchical trees (also shown in Figure 9). The corresponding search result displays the suitable building block(s) (step 2). This building block is subsequently selected (step 3) and exported to the spreadsheet application. The supporting Visual Basic macro automatically generates the cost model (step 4) that belongs to the building block(s). After this, the user is free to make choices and changes in the spreadsheet environment to arrive at customised process time and cost estimates (step 5). The changes can be checked against the existing knowledge base as a 'live link' is maintained between the two applications. If necessary, the knowledge base can be manually updated to support knowledge evolution (step 6).

Figure 10: Knowledge-based cost modelling solution - user process The user process (Figure 10) has been validated at the OEM company through the above exemplar and through expert opinion and user feedback. The functional solution itself is validated through its successful application in practice, for which a representative proofof-concept example has been presented herein. The validation exercise was specifically 


\section{W.J.C. Verhagen et al.}

designed so that the knowledge-based cost modelling solution addressed the three key identified fundamental knowledge management research elements.

Firstly, the solution to the case study provided knowledge life-cycle management through the inherit capabilities of the AKM tool and through the chosen solution methodology. In particular, the provisions for explicating the justification behind knowledge elements, the 'live link' between the knowledge base and the spreadsheet application, and the possibility to track the evolution of knowledge through the retention of historical knowledge articles contribute to a significant improvement on the life-cycle aspect.

Secondly, the solution also facilitated knowledge exploitation through the retention and exploitation of existing and legacy models, e.g. spreadsheet use, which ensured that users keep using familiar tools and processes. Furthermore, the use of a dedicated knowledge base, with the associated provisions to ensure the availability of trustworthy knowledge, assures users that the right knowledge is available at the right time.

Thirdly, the solution addressed knowledge visibility by including provision for knowledge explication. The difficulty with actually understanding complicated or dense legacy tools has been highlighted so that visibility is interpreted primarily in terms of the user being able to understand the rationale embedded into the tool. Users can adjust their confidence levels relative to the output results. Other features found to be of significance through the validation exercise included the traceability and retrievability of knowledge, potentially at the click of a mouse button. 


\section{$5 \quad$ Concluding remarks}

A framework and solution for knowledge-based cost modelling has been described in terms of its principles, methodology and architecture. Ultimately, a exemplar validation exercise was carried out. The developed solution delivers a key contribution from both a theoretical and practical perspective by enabling an integrated approach to performing process-based cost modelling supported by traceable, verifiable and reliable knowledge. More specifically, this solution makes it possible to:

- Manage cost modelling knowledge bases in tandem with operational use.

- Manage model and legacy tool complexity.

- Manage risk associated with current business processes.

- Provide an easier, more user-friendly cost modelling capacity that can consequently be understood and used by more end users, enabling a better and more distributed capacity for cost modelling in early-stage design.

The solution has advanced both research and business interests by addressing functional needs in enabling: a) the ability to manage the evolution of the knowledge from a lifecycle perspective; b) the ability to exploit cost modelling knowledge by fitting it into the existing business process and through seamless transfer of knowledge elements into a working cost model; and c) high visibility to the knowledge used in the cost model. The developed solution has been functionally validated as shown in the application example (Section 5.2) and has been accepted and validated by a world class industry lead as a distinct improvement upon the previous cost modelling solution. 


\section{W.J.C. Verhagen et al.}

In its current incarnation, the knowledge-based cost modelling solution is limited in several aspects. First, the whole process is at best semi-automatic. Composition of a cost model still requires some non-productive steps that don't add value, though the overall time spent on model composition is greatly reduced through the presented approach which produces something of great impact in a procedural and controllable manner.

Another limitation is the fact that the spreadsheet results from generated cost models and subsequent user manipulations are not yet stored into a central repository for the company; which is typical. The research has shown that it is advisable that these results are stored in such a repository for better understanding of the evolution of designs during the design process; this aspect will also be addressed in future research. A final limitation of the research that will addressed in future research is that the overall cost modelling capacity has not yet been fully addressed in informal terms: whereas the individual knowledge articles do feature informal knowledge, the higher-level process does not.

\section{Acknowledgments}

The authors would like to thank the various involved partners in the Next Generation Composite Wing Multi-Disciplinary Optimization of Wing project for their financial support of this research; we would like to thank Airbus UK in particular. We would also like to thank our EADS IW and Airbus UK collaborators, in particular Simon Astwood, Alistair Dare-Edwards, Kiran Krishnamurty, Dave Gore and Tom Gibbs, for their support.

\section{References}

Alavi, M., and Leidner, D.E., 2001. Review: Knowledge management and knowledge management systems: conceptual foundations and research issues. MIS Quarterly, 25 (1), 107-136.

Ammar-Khodja, S., and Bernard, A., 2008. An overview on knowledge management. In: A. Bernard and S. Tichkiewitch, eds. Methods and Tools for Effective Knowledge Life-Cycle-Management, Berlin: Springer, 3-21. 


\section{International Journal of Computer Integrated Manufacturing}

Airbus Next Generation Composite Wing. 2010. Available online at: http://www.aerospace.co.uk/technologies/ngcw.php [Accessed 02 February 2010].

Ardans SAS, 2010. Ardans Papiers Blancs. Available online at: http://www.ardans.fr/papiersBlancs.html [Accessed 01 February 2010].

Bermell-Garcia, P. and Fan, I., 2008. Practitioner requirements for integrated Knowledge-Based Engineering in Product Lifecycle Management. International Journal of Product Lifecycle Management, 3 (1), 3-20.

Choi, J.W., Kelly, D., and Raju, J., 2007. A knowledge-based engineering tool to estimate cost and weight of composite aerospace structures at the conceptual stage of the design process. Aircraft Engineering and Aerospace Technology: An International Journal, 79 (5), 459-468. DOI: 10.1108/00022660710780588

Curran, R., et al., 2003. Influence of Manufacturing Tolerance on Aircraft Direct Operating Cost (DOC). Journal of Materials Processing Technology, 138 (1-3), 208-213. ISSN 0924-0136, DOI: 10.1016/S0924-0136(03)00073-6.

Curran, R., Raghunathan, S., and Price, M., 2004. Review of aerospace engineering cost modelling: The genetic causal Approach. Progress in Aerospace Sciences, 40 (8), 487-534.

Curran, R., et al., 2006a. Modelling of aircraft manufacturing cost at the concept stage. The International Journal of Advanced Manufacturing Technology, 31 (3-4), 407420.

Curran, R., Rothwell, A., and Castagne, S., 2006b. Numerical Method for Cost-Weight Optimization of Stringer-Skin Panels. Journal of Aircraft, 43 (1), 264-274.

Curran, R., et al., 2007a. Aircraft Cost Modelling using the Genetic Causal Technique within a Systems Engineering Approach. The Aeronautical Journal, 111 (1121), 409-420.

Curran, R., et al., 2007b. Integrated Digital Design for Manufacture for Reduced Life Cycle Cost. International Journal of Production Economics, 109 (1-2), 27-40. ISSN 0925-5273, DOI: 10.1016/j.ijpe.2006.11.010.

Curran, R., Chou, S.-Y. and Trappey, A., 2008a. Collaborative Product and Service Life Cycle Management for a Sustainable World, Berlin: Springer. ISBN: 978-184800-971-4.

Curran, R., et al., 2008b. Cost Modelling of Composite Aerospace Parts and Assemblies. In: Proceedings of the 15th International Conference on Concurrent Engineering, Springer, ISBN 978-1-84800-971-4, 281-291.

Curran, R., et al., 2008c. Cost optimisation of tolerances and manufacturing capability for aircraft surface features. International Journal of Manufacturing Technology and Management, 15 (3-4), 298-319.

Curran, R., Verhagen, W.J.C., Van Tooren, M.J.L., and Van der Laan, A.H., 2010. Design Integration of Multidisciplinary Engineering Knowledge within a Knowledge-Based Engineering Framework: the KNOMAD Methodology. Expert Systems with Applications, Special Issue on Concurrent Engineering, in press.

Feldman, P., and Shtub, A., 2006. Model for cost estimation in a finite-capacity environment. International Journal of Production Research, 44 (2), 305-327.

Kulon, J., Mynors, D.J., and Broomhead, P., 2006. A knowledge-based engineering design tool for metal forging. Journal of Materials Processing Technology, 177, 331-335. DOI: 10.1016/j.jmatprotec.2006.04.062 
W.J.C. Verhagen et al.

Mariot, P., et al., 2007a. Méthode, Modèle et Outil Ardans de capitalisation des connaissances. In: Cepadues, ed. Revues des Nouvelles Technologies de l'Information, RNTI E-12,7èmes journées francophones Extraction et Gestion des Connaissances, Namur, Belgique, 187-207.

Mariot, P., et al., 2007b. Querying multiple sources with OWL ontologies: an exploratory study in an automotive company. In : OWLED 2007 - CEUR Workshop

Proceedings, Innsbrück, Austria. ISSN 1613-0073. Available online: http://sunsite.informatik.rwth-aachen.de/Publications/CEUR-WS/Vol258/paper08.pdf

McMahon, C., Giess, M. and Culley, S., 2005. Information management for through-life product support: the curation of digital engineering data. International Journal of Product Lifecycle Management, 1 (1), 26-42.

Newnes, L.B., et al., 2008. Predicting the whole-life cost of a product at the conceptual design stage. Journal of Engineering Design, 19 (2), 99 - 112.

NIST: Manufacturing Engineering Laboratory, 2007. Manufacturing Interoperability Programmee. Available online at: http://www.mel.nist.gov/proj/mi.htm [Accessed 01-03-2010]

Nonaka, I., 1994. A dynamic theory of organizational knowledge creation. Organization Science, 5 (1), 14-37.

Oldham, K., et al., 1999. MOKA - A methodology for developing KBE applications. In: Proceedings of the 8th European Conference on Product Data Technology, Stavanger, Norway, 361-366.

Preston, S., et al., 2005. Knowledge acquisition for knowledge-based engineering systems. International Journal of Information Technology and Management, 4 (1), 1-11.

Price, M., Raghunathan, S. and Curran, R., 2006. An integrated systems engineering approach to aircraft design. Progress in Aerospace Sciences, 42 (4), 331-376.

Redon, R., et al., 2007. VIVACE Context Based Search Platform. In: P. Brezillon, B. Kokinov, G. Petkov, eds. CONTEXT 2007: Proceedings of the 6th International and Interdisciplinary Conference, August 20-24, 2007, Roskilde, Denmark. Berlin: Springer, 397-410. DOI: 10.1007/978-3-540-74255-5

Schreiber, G., et al., 1999, Knowledge Engineering and Management: the CommonKADS methodology. Cambridge, MA: MIT Press.

Siemieniuch, C.E., and Sinclair, M.A., 1999. Organizational aspects of knowledge lifecycle management in manufacturing. International Journal of HumanComputer Studies, 51 (3), 517-546.

Skarka, W., 2007. Application of MOKA methodology in generative model creation using CATIA. Engineering Applications of Artificial Intelligence, 20, 677-690. DOI: 10.1016/j.engappai.2006.11.019

Stokes, M., ed., 2001. Managing Engineering Knowledge - MOKA: Methodology for Knowledge Based Engineering Applications. London: Professional Engineering Publishing Limited.

Sudarsan R., et al., 2005. A product information modeling framework for product lifecycle management, CAD Computer Aided Design, 37 (13), 1399-1411.

Technology Strategy Board, 2009. Affordable Composites Manufacturing. Available online at: http://www.innovateuk.org/_assets/pdf/competition- 
documents/affordablecompositesmanufacturingcompflyer.pdf [Accessed 02-032010]

Umeda, Y., et al., 1996. Supporting conceptual design based on the function-behaviorstate modeler. Artificial intelligence for engineering design, analysis and manufacturing, 10 (4), 275-288. 


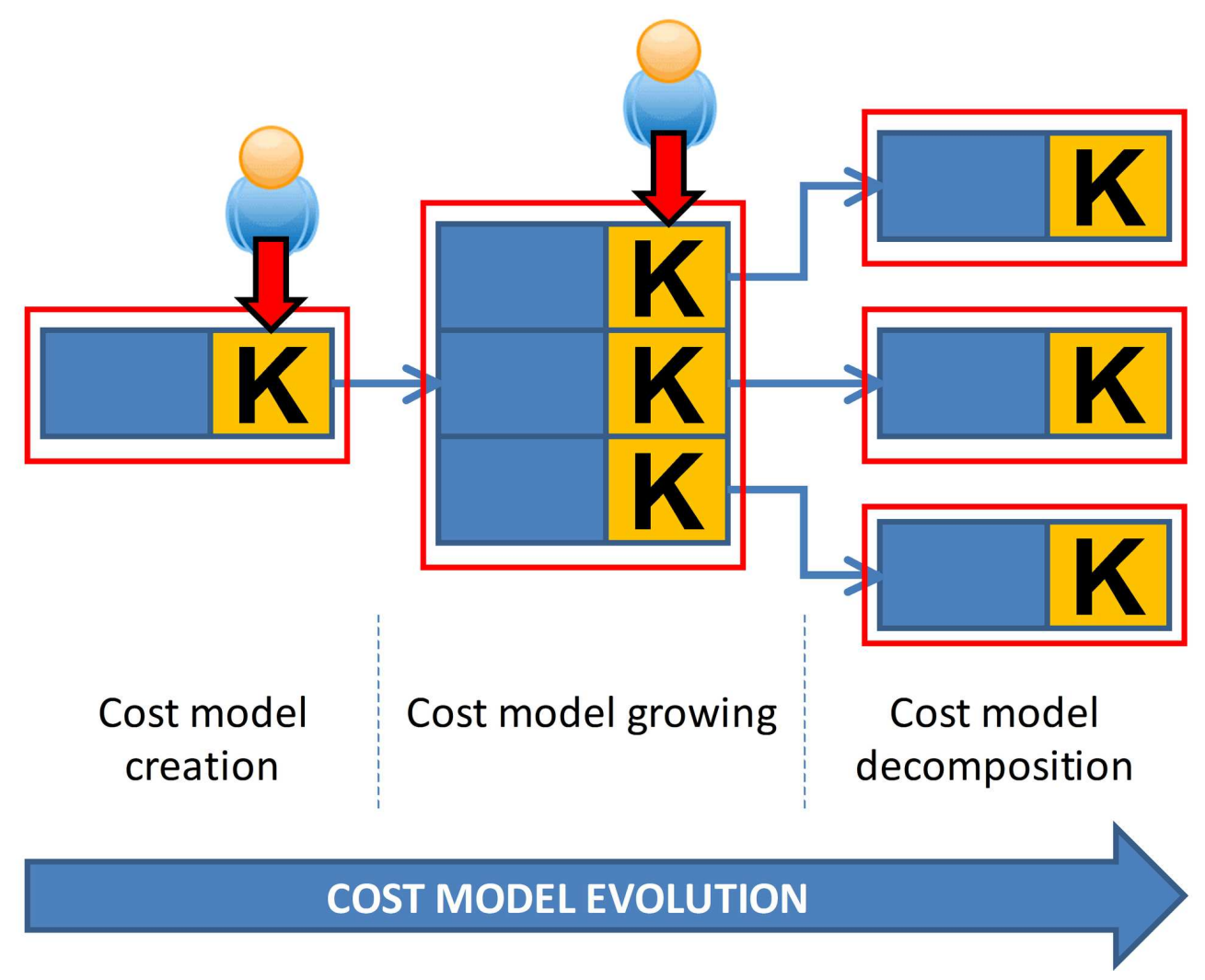

Cost model evolution $83 \times 68 \mathrm{~mm}(600 \times 600 \mathrm{DPI})$ 


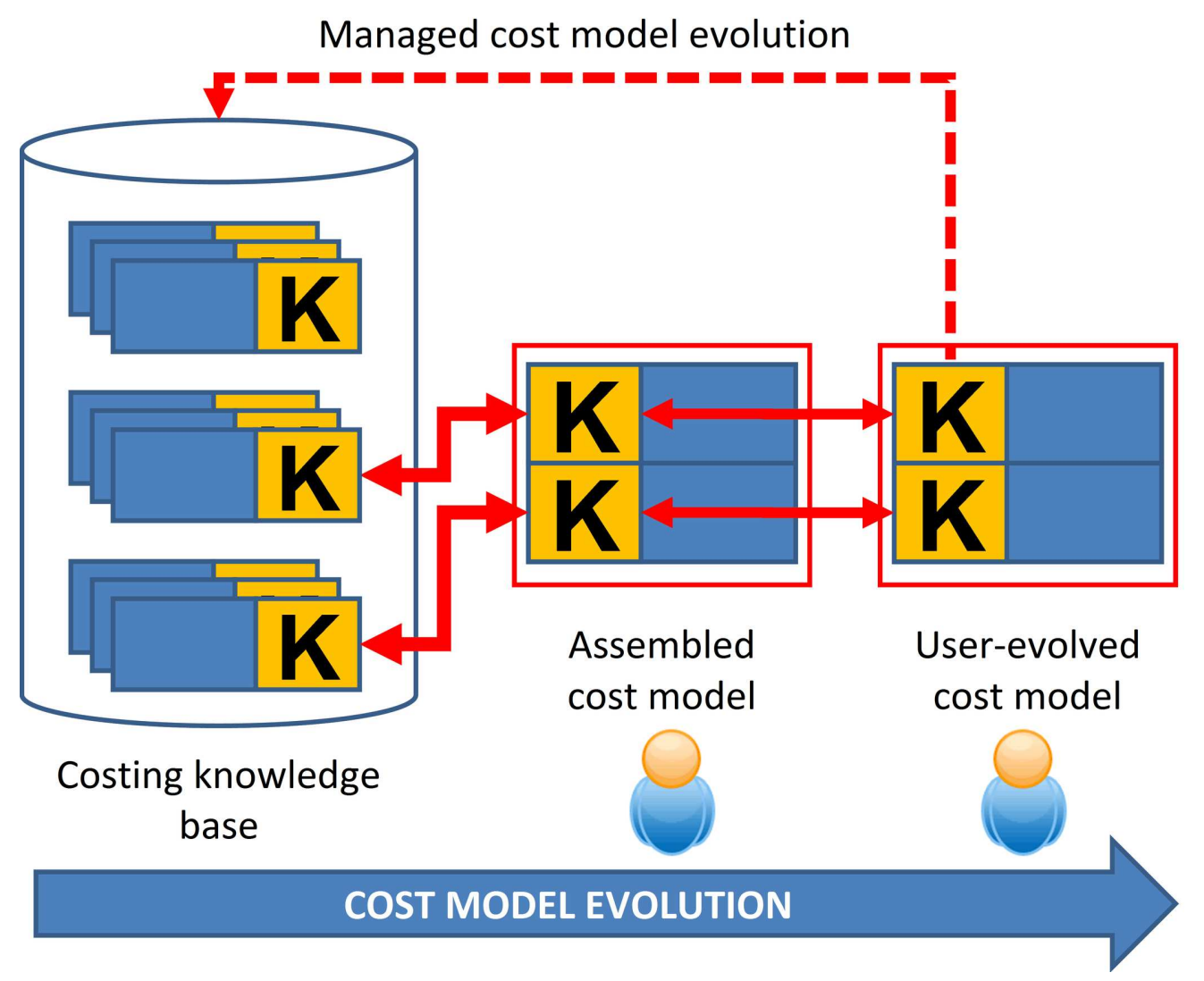

Managed cost model evolution $87 \times 73 \mathrm{~mm}(600 \times 600 \mathrm{DPI})$ 




Cost model - generic process

$83 \times 65 \mathrm{~mm}(600 \times 600 \mathrm{DPI})$ 


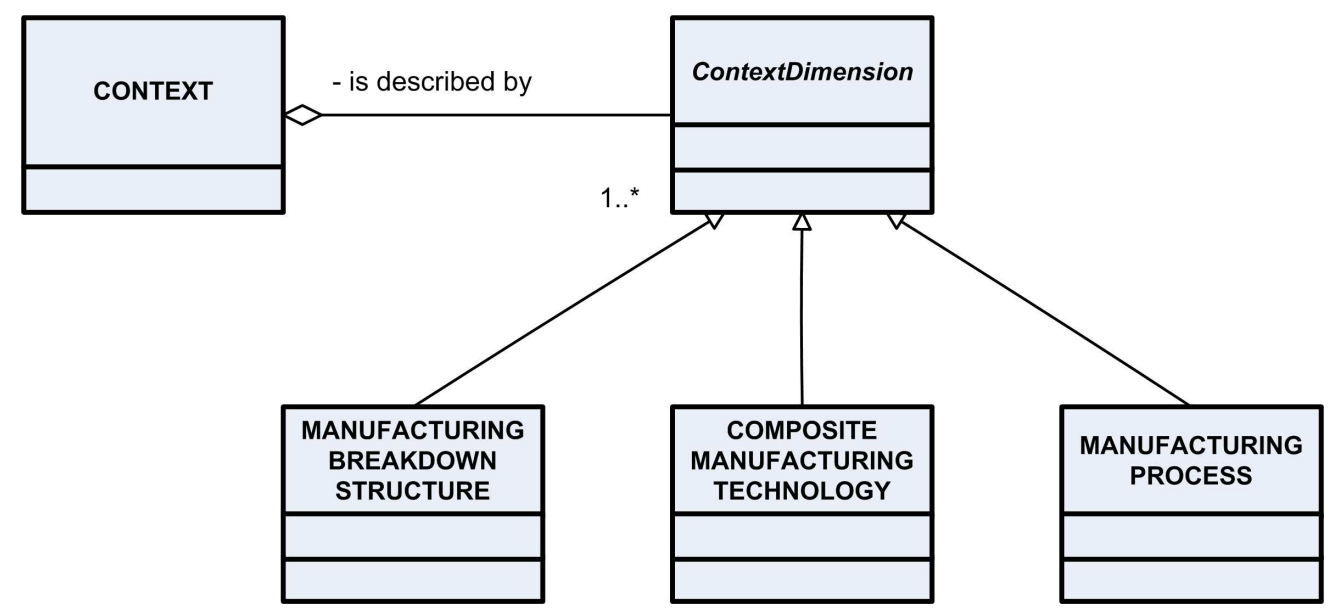

Contextual description model for cost modelling of composite structures $100 \times 45 \mathrm{~mm}(600 \times 600 \mathrm{DPI})$ 


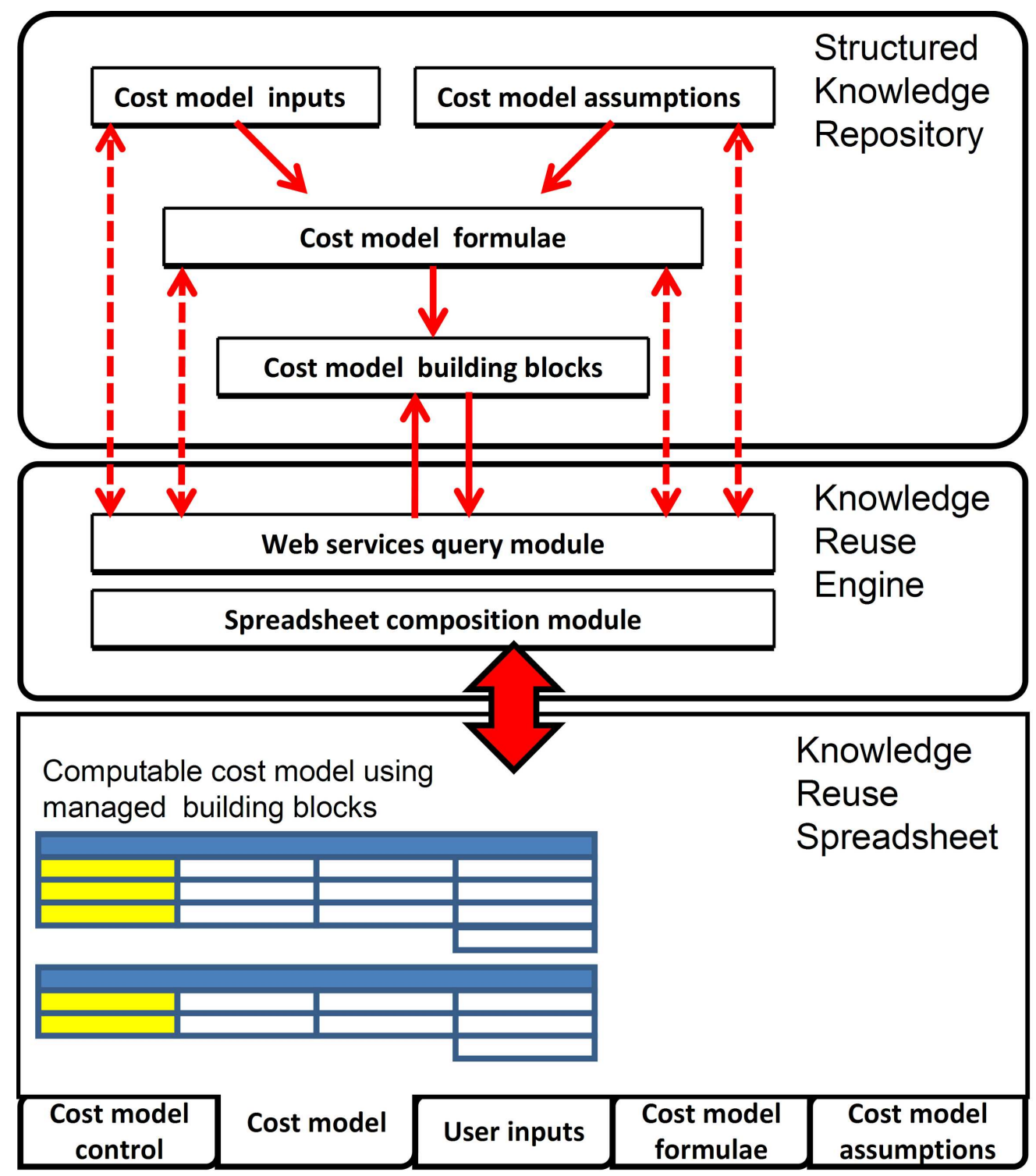

Implementation architecture $98 \times 112 \mathrm{~mm}(600 \times 600$ DPI $)$ 


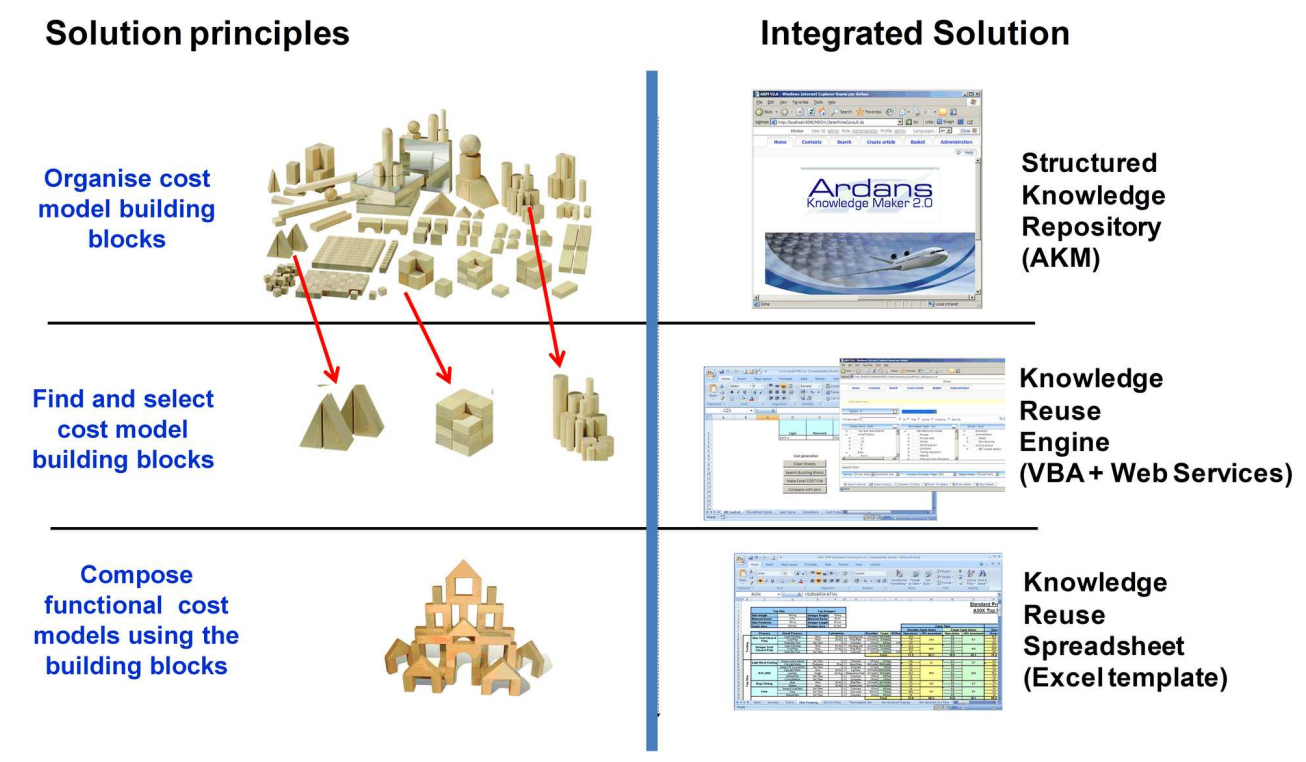

Overview of solution principles (left) and integrated solution (right) $84 \times 49 \mathrm{~mm}(600 \times 600$ DPI $)$ 


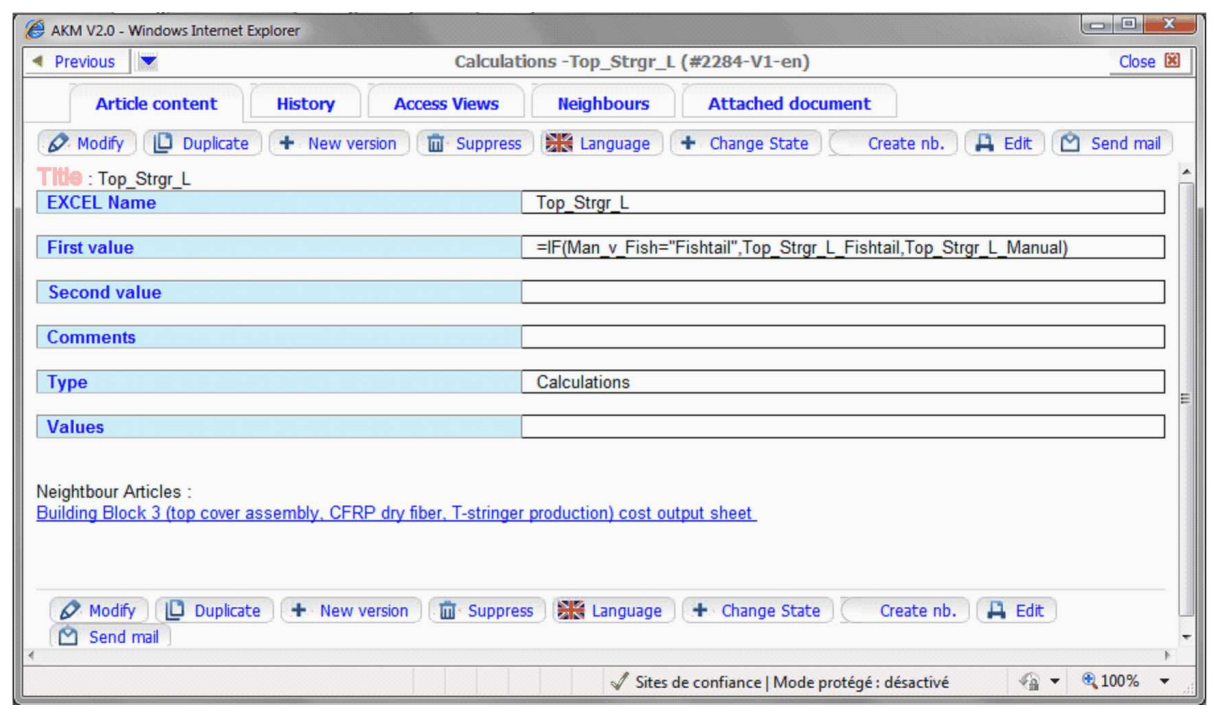

AKM knowledge article example $80 \times 43 \mathrm{~mm}(600 \times 600 \mathrm{DPI})$ 


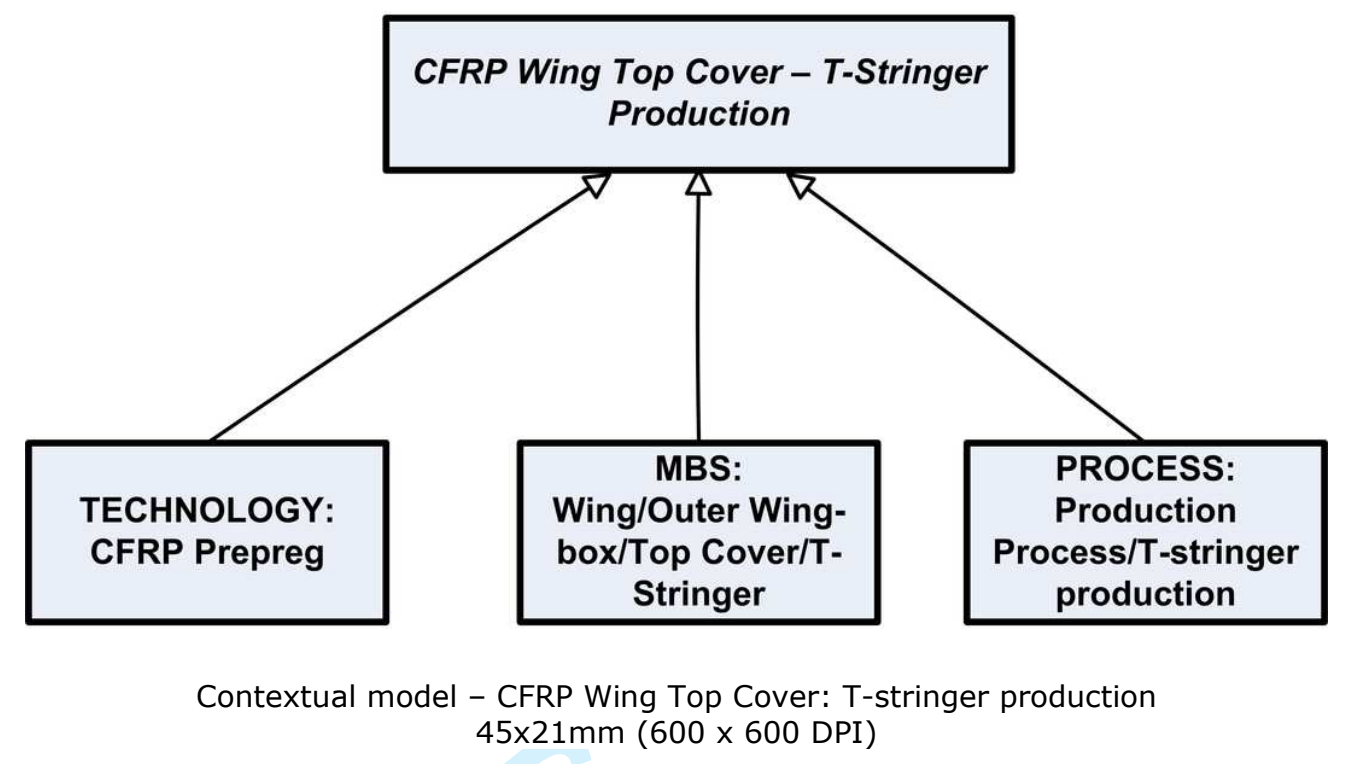

URL: http://mc.manuscriptcentral.com/tandf/tcim Email:ijcim@bath.ac.uk 


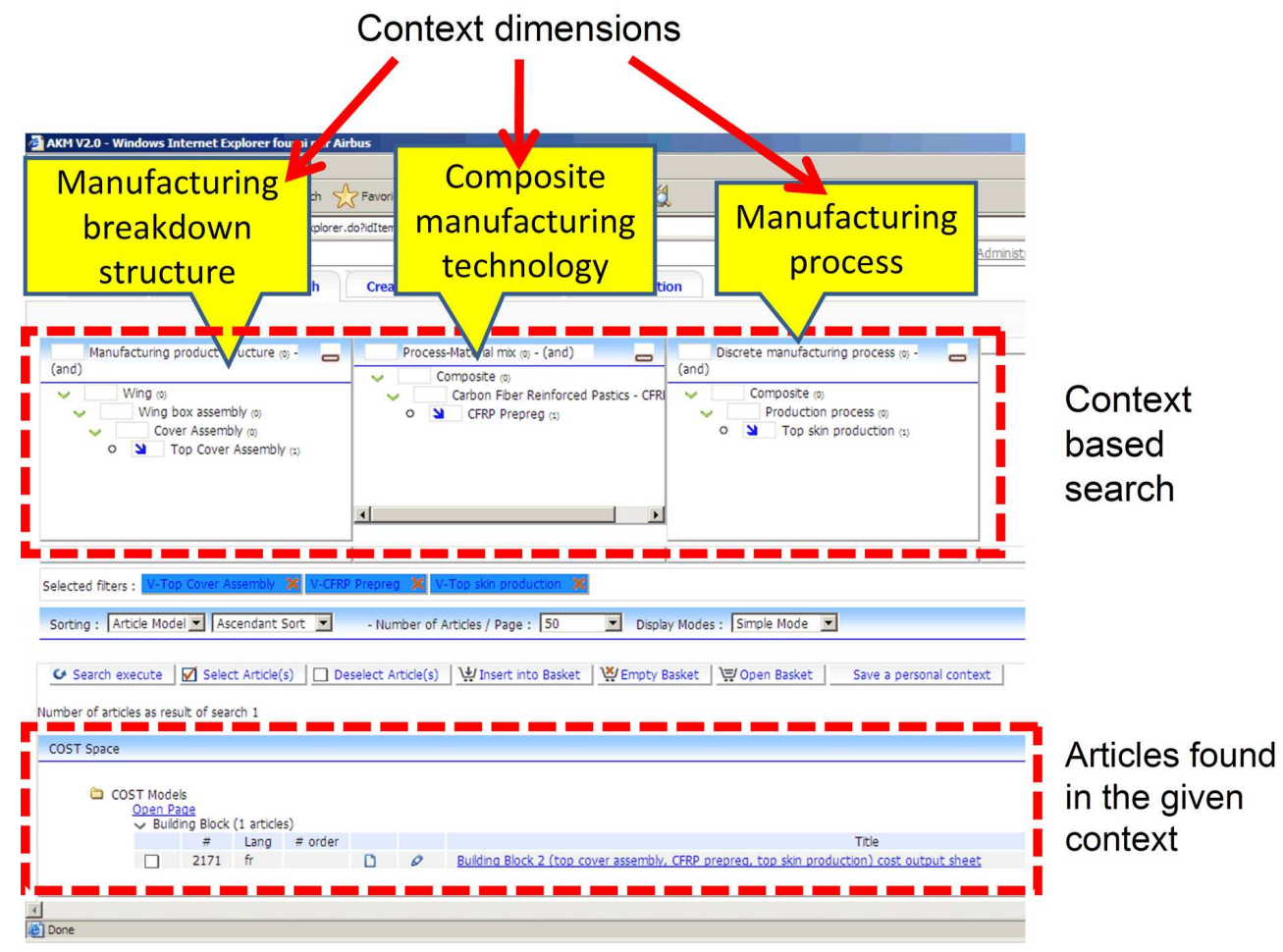

AKM search environment - hierarchical knowledge representations $81 \times 60 \mathrm{~mm}(600 \times 600 \mathrm{DPI})$ 


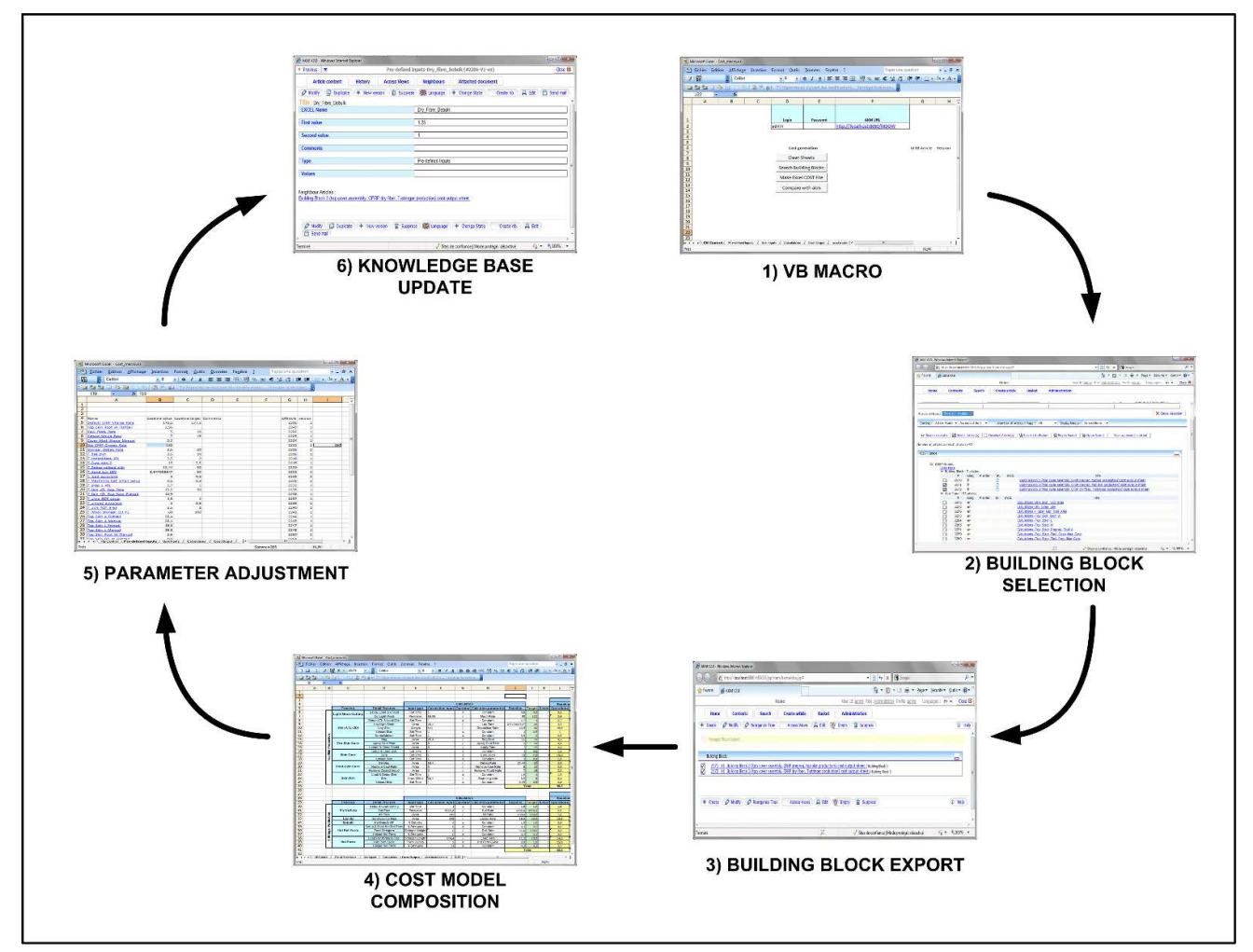

Knowledge-based cost modelling solution - user process $134 \times 111 \mathrm{~mm}(600 \times 600 \mathrm{DPI})$ 


\begin{tabular}{|c|c|c|}
\hline Approach & Advantages & Disadvantages \\
\hline Bottom-up costing & $\begin{array}{l}\text { Cause and effect understood } \\
\text { Very detailed estimate }\end{array}$ & $\begin{array}{l}\text { Difficult to develop and implement } \\
\text { Substantial, detailed expert data are } \\
\text { required } \\
\text { Requires expert knowledge }\end{array}$ \\
\hline Analogous costing & $\begin{array}{l}\text { Cause and effect understood } \\
\text { More easily applied than bottom- } \\
\text { up method }\end{array}$ & $\begin{array}{l}\text { Appropriate baseline must exist } \\
\text { Substantial, detailed data are required } \\
\text { Requires expert knowledge }\end{array}$ \\
\hline Parametric costing & $\begin{array}{l}\text { Easiest to implement } \\
\text { Non-technical experts can apply } \\
\text { method } \\
\text { Uncertainty of the forecast is } \\
\text { generated } \\
\text { Allows scope for quantifying risk }\end{array}$ & $\begin{array}{l}\text { Can be difficult to develop } \\
\text { Factors might be associative but not } \\
\text { causative } \\
\text { Extrapolation of existing data to } \\
\text { forecast future products including } \\
\text { new developments might be } \\
\text { unwarranted }\end{array}$ \\
\hline
\end{tabular}

Assessment matrix for traditional cost estimation methods (Curran et al., 2004) $73 \times 42 \mathrm{~mm}(600 \times 600 \mathrm{DPI})$ 


\begin{tabular}{|c|c|c|c|c|c|c|c|c|}
\hline \multicolumn{9}{|c|}{ Analysis Discipline } \\
\hline & & Aerodynamics & $\begin{array}{l}\text { Structures } \\
\text { \& weights }\end{array}$ & Noise & Geometry & Cost & Manufacturing & Maintenance \\
\hline \multirow{3}{*}{ 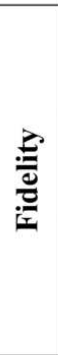 } & Low & $\begin{array}{l}\text { Empirical } \\
\text { methods (e.g. } \\
\text { EDET) }\end{array}$ & $\begin{array}{l}\text { Empirical } \\
\text { methods } \\
\text { (e.g. } \\
\text { FLOPS) }\end{array}$ & $\begin{array}{c}\text { Empirical } \\
\text { methods } \\
\text { (e.g. } \\
\text { FLOPS) }\end{array}$ & $\begin{array}{c}\text { Vehicle } \\
\text { Sketch Pad } \\
\text { (VSP) }\end{array}$ & $\begin{array}{l}\text { Piano, } \\
\text { SEER, } \\
\text { Price }\end{array}$ & GAP & GAP \\
\hline & Medium & $\begin{array}{l}\text { Vortex Lattice } \\
\text { (e.g. } \\
\text { WINGDES) }\end{array}$ & $\begin{array}{c}\text { Basic } \\
\text { structures } \\
\text { (e.g. } \\
\text { ELAPS) }\end{array}$ & $\begin{array}{c}\text { Basic } \\
\text { Noise (e.g. } \\
\text { ANOPP) }\end{array}$ & GAP & GAP & GAP & GAP \\
\hline & High & $\begin{array}{c}\text { CFD (e.g. } \\
\text { FUN2D, Fluent) }\end{array}$ & $\begin{array}{l}\text { FEM (e.g. } \\
\text { NASTRAN) }\end{array}$ & $\begin{array}{l}\text { Advanced } \\
\text { Noise (e.g. } \\
\text { AVATAR) }\end{array}$ & $\begin{array}{l}\text { High-end } \\
\text { CAD } \\
\text { systems } \\
\text { (e.g. } \\
\text { CATIA) }\end{array}$ & GAP & $\begin{array}{l}\text { Virtual Factory } \\
\text { Simulations (e.g. } \\
\text { DELMIA) }\end{array}$ & GAP \\
\hline
\end{tabular}

Disciplines versus fidelity (modified from Price et al., 2006) $54 \times 20 \mathrm{~mm}(600 \times 600$ DPI $)$ 


\begin{tabular}{|c|c|c|c|c|c|c|c|}
\hline & Process & Detail Process & & tio & & Baseline & Target \\
\hline \multirow{14}{*}{ 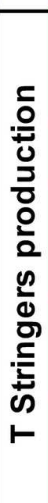 } & \multirow{3}{*}{ Strgr ATL (2D) } & Setup ATL \& Load Tool & Set Time & $x$ & Constant & & \\
\hline & & Lay Slab & Weight & 1 & Deposition Rate & & \\
\hline & & Unload ATL & Set Time & $\mathrm{x}$ & Constant & & \\
\hline & \multirow{2}{*}{ Strgr ATL (2D) Cut \& Kit } & Cut Slab into Planforms & Slab Perimeter & 1 & Cut Rate & & \\
\hline & & Kit Planforms & N Stringer pieces & $x$ & Constant & & \\
\hline & \multirow{3}{*}{ Strgr Hot Roll Form } & Setup \& Soak Hot Roll Form & $\mathrm{N}$ Stringers & $\bar{x}$ & Constant & & \\
\hline & & Feed Stringers & Stringer Weight & 1 & Roll Rate & & \\
\hline & & Unload Hot Form & $N$ Stringers & $\mathrm{x}$ & Constant & & \\
\hline & \multirow{3}{*}{ Strgr Hot Form } & Load Planforms to Tool & Stringer Length & 7 & Load Rate & & \\
\hline & & Hot Form Cycle & Form Cycles & $x$ & Hot Form Cycle & & \\
\hline & & Unload Hot Form & N Stringers & $x$ & Constant & & \\
\hline & \multirow{3}{*}{ Stringer Profile Shape } & Position Blade & N Stringers & $\bar{x}$ & Constant & & \\
\hline & & Make Final Profile & N Stringers & $x$ & Constant & & \\
\hline & & Insert Noodle & Length & 1 & Rate & & \\
\hline
\end{tabular}

Predefined Manufacturing Process: T-stringer Production - Initial Parameters $70 \times 35 \mathrm{~mm}(600 \times 600 \mathrm{DPI})$ 


\section{ELSEVIER LICENSE \\ TERMS AND CONDITIONS}

Jul 27, 2010

This is a License Agreement between Wim Verhagen ("You") and Elsevier ("Elsevier") provided by Copyright Clearance Center ("CCC"). The license consists of your order details, the terms and conditions provided by Elsevier, and the payment terms and conditions.

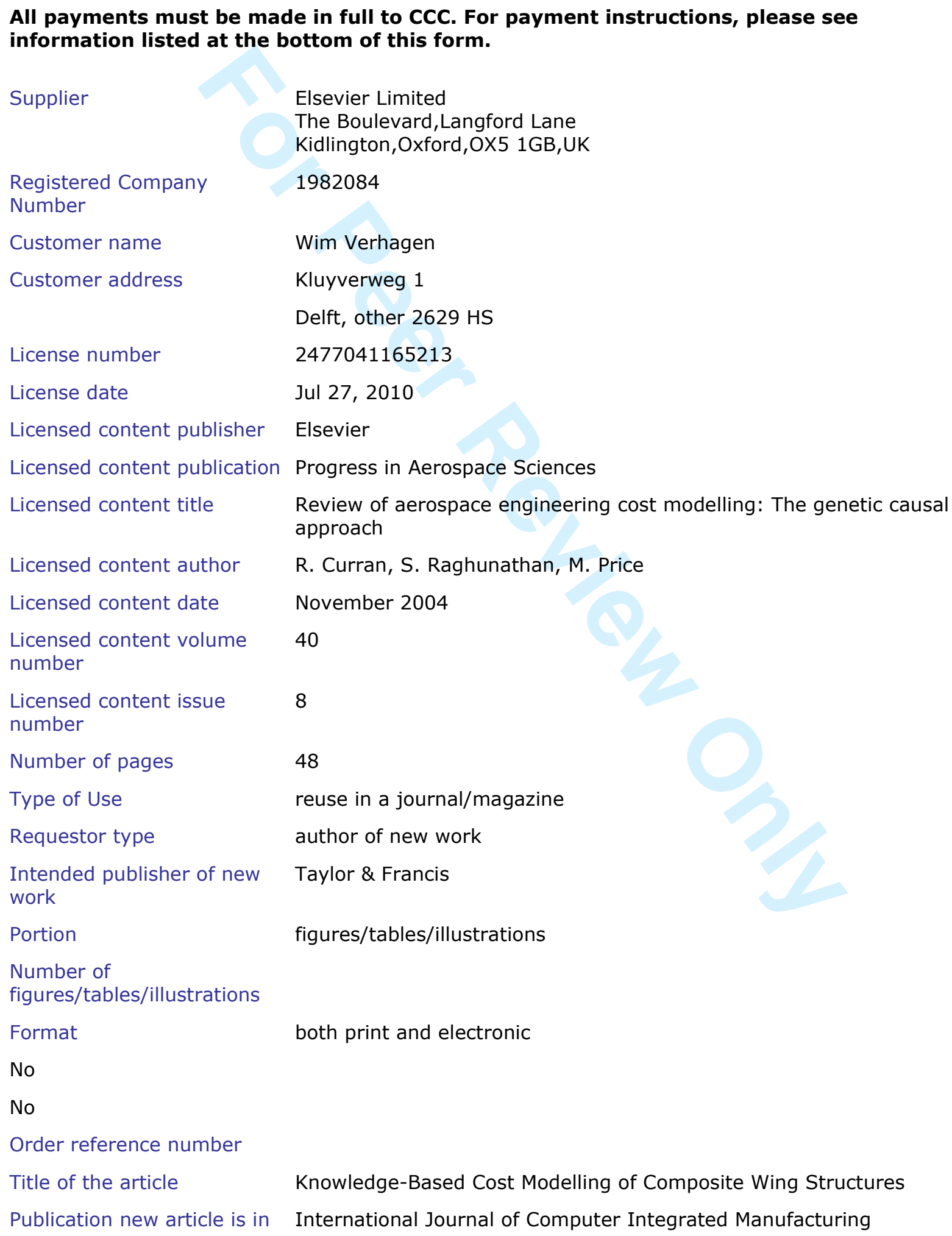

Supplier

Registered Company

Number

Customer name

Customer address

License number

License date

Licensed content publisher

Licensed content publication

Licensed content title

Licensed content author

Licensed content date

Licensed content volume number

Licensed content issue number

Number of pages

Type of Use

Requestor type

Intended publisher of new work

Portion

Number of

figures/tables/illustrations

Format

No

No

Order reference number

Title of the article

Publication new article is in

Elsevier Limited

The Boulevard,Langford Lane

Kidlington,Oxford,OX5 1GB,UK

1982084

Wim Verhagen

Kluyverweg 1

Delft, other 2629 HS

2477041165213

Jul 27, 2010

Elsevier

Progress in Aerospace Sciences

Review of aerospace engineering cost modelling: The genetic causal approach

R. Curran, S. Raghunathan, M. Price

November 2004

40

8

48

reuse in a journal/magazine

author of new work

Taylor \& Francis

figures/tables/illustrations

both print and electronic

Knowledge-Based Cost Modelling of Composite Wing Structures

International Journal of Computer Integrated Manufacturing

URL: http://mc.manuscriptcentral.com/tandf/tcim Email:ijcim@bath.ac.uk

https://s100.copyright.com/App/PrintableLicenseFrame.jsp?publisherID=70\&licenseI... 27-7-2010 


\author{
Publisher of new work Taylor \& Francis \\ Author of new article \\ W.J.C. Verhagen \\ Expected publication date \\ Dec 2010 \\ Estimated size of new article 18 \\ (number of pages) \\ Elsevier VAT number \\ GB 494627212 \\ Terms and Conditions
}

\title{
INTRODUCTION
}

1. The publisher for this copyrighted material is Elsevier. By clicking "accept" in connection with completing this licensing transaction, you agree that the following terms and conditions apply to this transaction (along with the Billing and Payment terms and conditions established by Copyright Clearance Center, Inc. ("CCC"), at the time that you opened your Rightslink account and that are available at any time at http://myaccount.copyright.com).

\section{GENERAL TERMS}

2. Elsevier hereby grants you permission to reproduce the aforementioned material subject to the terms and conditions indicated.

3. Acknowledgement: If any part of the material to be used (for example, figures) has appeared in our publication with credit or acknowledgement to another source, permission must also be sought from that source. If such permission is not obtained then that material may not be included in your publication/copies. Suitable acknowledgement to the source must be made, either as a footnote or in a reference list at the end of your publication, as follows:

"Reprinted from Publication title, Vol /edition number, Author(s), Title of article / title of chapter, Pages No., Copyright (Year), with permission from Elsevier [OR APPLICABLE SOCIETY COPYRIGHT OWNER]." Also Lancet special credit - "Reprinted from The Lancet, Vol. number, Author(s), Title of article, Pages No., Copyright (Year), with permission from Elsevier."

4. Reproduction of this material is confined to the purpose and/or media for which permission is hereby given.

5. Altering/Modifying Material: Not Permitted. However figures and illustrations may be altered/adapted minimally to serve your work. Any other abbreviations, additions, deletions and/or any other alterations shall be made only with prior written authorization of Elsevier Ltd. (Please contact Elsevier at permissions@elsevier.com)

6. If the permission fee for the requested use of our material is waived in this instance, please be advised that your future requests for Elsevier materials may attract a fee.

7. Reservation of Rights: Publisher reserves all rights not specifically granted in the combination of (i) the license details provided by you and accepted in the course of this licensing transaction, (ii) these terms and conditions and (iii) CCC's Billing and Payment terms and conditions.

8. License Contingent Upon Payment: While you may exercise the rights licensed immediately upon issuance of the license at the end of the licensing process for the 
transaction, provided that you have disclosed complete and accurate details of your proposed use, no license is finally effective unless and until full payment is received from you (either by publisher or by CCC) as provided in CCC's Billing and Payment terms and conditions. If full payment is not received on a timely basis, then any license preliminarily granted shall be deemed automatically revoked and shall be void as if never granted. Further, in the event that you breach any of these terms and conditions or any of CCC's Billing and Payment terms and conditions, the license is automatically revoked and shall be void as if never granted. Use of materials as described in a revoked license, as well as any use of the materials beyond the scope of an unrevoked license, may constitute copyright infringement and publisher reserves the right to take any and all action to protect its copyright in the materials.

9. Warranties: Publisher makes no representations or warranties with respect to the licensed material.

10. Indemnity: You hereby indemnify and agree to hold harmless publisher and CCC, and their respective officers, directors, employees and agents, from and against any and all claims arising out of your use of the licensed material other than as specifically authorized pursuant to this license.

11. No Transfer of License: This license is personal to you and may not be sublicensed, assigned, or transferred by you to any other person without publisher's written permission.

12. No Amendment Except in Writing: This license may not be amended except in a writing signed by both parties (or, in the case of publisher, by CCC on publisher's behalf).

13. Objection to Contrary Terms: Publisher hereby objects to any terms contained in any purchase order, acknowledgment, check endorsement or other writing prepared by you, which terms are inconsistent with these terms and conditions or CCC's Billing and Payment terms and conditions. These terms and conditions, together with CCC's Billing and Payment terms and conditions (which are incorporated herein), comprise the entire agreement between you and publisher (and CCC) concerning this licensing transaction. In the event of any conflict between your obligations established by these terms and conditions and those established by CCC's Billing and Payment terms and conditions, these terms and conditions shall control.

14. Revocation: Elsevier or Copyright Clearance Center may deny the permissions described in this License at their sole discretion, for any reason or no reason, with a full refund payable to you. Notice of such denial will be made using the contact information provided by you. Failure to receive such notice will not alter or invalidate the denial. In no event will Elsevier or Copyright Clearance Center be responsible or liable for any costs, expenses or damage incurred by you as a result of a denial of your permission request, other than a refund of the amount(s) paid by you to Elsevier and/or Copyright Clearance Center for denied permissions.

\section{LIMITED LICENSE}

The following terms and conditions apply only to specific license types:

15. Translation: This permission is granted for non-exclusive world English rights only unless your license was granted for translation rights. If you licensed translation rights you may only translate this content into the languages you requested. A professional translator must perform all translations and reproduce the content word for word preserving the integrity of the article. If this license is to re-use 1 or 2 figures then permission is granted for 
non-exclusive world rights in all languages.

16. Website: The following terms and conditions apply to electronic reserve and author websites:

Electronic reserve: If licensed material is to be posted to website, the web site is to be password-protected and made available only to bona fide students registered on a relevant course if:

This license was made in connection with a course,

This permission is granted for 1 year only. You may obtain a license for future website posting,

All content posted to the web site must maintain the copyright information line on the bottom of each image,

A hyper-text must be included to the Homepage of the journal from which you are licensing at http://www.sciencedirect.com/science/journal/xxxxx or the Elsevier homepage for books at http://www.elsevier.com, and

Central Storage: This license does not include permission for a scanned version of the material to be stored in a central repository such as that provided by Heron/XanEdu.

17. Author website for journals with the following additional clauses:

All content posted to the web site must maintain the copyright information line on the bottom of each image, and

he permission granted is limited to the personal version of your paper. You are not allowed to download and post the published electronic version of your article (whether PDF or HTML, proof or final version), nor may you scan the printed edition to create an electronic version,

A hyper-text must be included to the Homepage of the journal from which you are licensing at http://www.sciencedirect.com/science/journal/xxxxx , As part of our normal production process, you will receive an e-mail notice when your article appears on Elsevier's online service ScienceDirect (www.sciencedirect.com). That e-mail will include the article's Digital Object Identifier (DOI). This number provides the electronic link to the published article and should be included in the posting of your personal version. We ask that you wait until you receive this e-mail and have the DOI to do any posting.

Central Storage: This license does not include permission for a scanned version of the material to be stored in a central repository such as that provided by Heron/XanEdu.

18. Author website for books with the following additional clauses:

Authors are permitted to place a brief summary of their work online only.

A hyper-text must be included to the Elsevier homepage at http://www.elsevier.com

All content posted to the web site must maintain the copyright information line on the bottom of each image

You are not allowed to download and post the published electronic version of your chapter, nor may you scan the printed edition to create an electronic version.

Central Storage: This license does not include permission for a scanned version of the material to be stored in a central repository such as that provided by Heron/XanEdu.

19. Website (regular and for author): A hyper-text must be included to the Homepage of the journal from which you are licensing at

http://www.sciencedirect.com/science/journal/xxxxx. or for books to the Elsevier homepage at http://www.elsevier.com 
20. Thesis/Dissertation: If your license is for use in a thesis/dissertation your thesis may be submitted to your institution in either print or electronic form. Should your thesis be published commercially, please reapply for permission. These requirements include permission for the Library and Archives of Canada to supply single copies, on demand, of the complete thesis and include permission for UMI to supply single copies, on demand, of the complete thesis. Should your thesis be published commercially, please reapply for permission.

\section{Other Conditions:}

\section{v1.6}

Gratis licenses (referencing $\$ 0$ in the Total field) are free. Please retain this printable license for your reference. No payment is required.

If you would like to pay for this license now, please remit this license along with your payment made payable to "COPYRIGHT CLEARANCE CENTER" otherwise you will be invoiced within $\mathbf{4 8}$ hours of the license date. Payment should be in the form of a check or money order referencing your account number and this invoice number RLNK10821559.

Once you receive your invoice for this order, you may pay your invoice by credit card. Please follow instructions provided at that time.

Make Payment To:

Copyright Clearance Center

Dept 001

P.O. Box 843006

Boston, MA 02284-3006

If you find copyrighted material related to this license will not be used and wish to cancel, please contact us referencing this license number 2477041165213 and noting the reason for cancellation.

Questions? customercare@copyright.com or +1-877-622-5543 (toll free in the US) or +1-978-646-2777. 


\section{ELSEVIER LICENSE TERMS AND CONDITIONS}

Jul 27, 2010

This is a License Agreement between Wim Verhagen ("You") and Elsevier ("Elsevier") provided by Copyright Clearance Center ("CCC"). The license consists of your order details, the terms and conditions provided by Elsevier, and the payment terms and conditions.



Supplier

Registered Company

Number

Customer name

Customer address

License number

License date

Licensed content publisher

Licensed content publication

Licensed content title

Licensed content author

Licensed content date

Licensed content volume number

Licensed content issue

number

Number of pages

Type of Use

Requestor type

Intended publisher of new work

Portion

Number of

figures/tables/illustrations

Format

No

No

Order reference number

Title of the article

Publication new article is in

Publisher of new work

Elsevier Limited

The Boulevard,Langford Lane

Kidlington,Oxford,OX5 1GB,UK

1982084

Wim Verhagen

Kluyverweg 1

Delft, other 2629 HS

\section{5}

Jul 27, 2010

Elsevier

Progress in Aerospace Sciences

An integrated systems engineering approach to aircraft design

M. Price, S. Raghunathan, R. Curran

June 2006

42

4

46

reuse in a journal/magazine

author of new work

Taylor \& Francis

figures/tables/illustrations

both print and electronic

Knowledge-Based Cost Modelling of Composite Wing Structures

International Journal of Computer Integrated Manufacturing

Taylor \& Francis

URL: http://mc.manuscriptcentral.com/tandf/tcim Email:ijcim@bath.ac.uk https://s100.copyright.com/App/PrintableLicenseFrame.jsp?publisherID=70\&licenseI... 27-7-2010 


\author{
Author of new article W.J.C. Verhagen \\ Expected publication date Dec 2010 \\ Estimated size of new article 18 \\ (number of pages)
}

Elsevier VAT number $\quad$ GB 494627212

Terms and Conditions

\title{
INTRODUCTION
}

1. The publisher for this copyrighted material is Elsevier. By clicking "accept" in connection with completing this licensing transaction, you agree that the following terms and conditions apply to this transaction (along with the Billing and Payment terms and conditions established by Copyright Clearance Center, Inc. ("CCC"), at the time that you opened your Rightslink account and that are available at any time at http://myaccount.copyright.com).

\section{GENERAL TERMS}

2. Elsevier hereby grants you permission to reproduce the aforementioned material subject to the terms and conditions indicated.

3. Acknowledgement: If any part of the material to be used (for example, figures) has appeared in our publication with credit or acknowledgement to another source, permission must also be sought from that source. If such permission is not obtained then that material may not be included in your publication/copies. Suitable acknowledgement to the source must be made, either as a footnote or in a reference list at the end of your publication, as follows:

"Reprinted from Publication title, Vol /edition number, Author(s), Title of article / title of chapter, Pages No., Copyright (Year), with permission from Elsevier [OR APPLICABLE SOCIETY COPYRIGHT OWNER]." Also Lancet special credit - "Reprinted from The Lancet, Vol. number, Author(s), Title of article, Pages No., Copyright (Year), with permission from Elsevier."

4. Reproduction of this material is confined to the purpose and/or media for which permission is hereby given.

5. Altering/Modifying Material: Not Permitted. However figures and illustrations may be altered/adapted minimally to serve your work. Any other abbreviations, additions, deletions and/or any other alterations shall be made only with prior written authorization of Elsevier Ltd. (Please contact Elsevier at permissions@elsevier.com)

6. If the permission fee for the requested use of our material is waived in this instance, please be advised that your future requests for Elsevier materials may attract a fee.

7. Reservation of Rights: Publisher reserves all rights not specifically granted in the combination of (i) the license details provided by you and accepted in the course of this licensing transaction, (ii) these terms and conditions and (iii) CCC's Billing and Payment terms and conditions.

8. License Contingent Upon Payment: While you may exercise the rights licensed immediately upon issuance of the license at the end of the licensing process for the transaction, provided that you have disclosed complete and accurate details of your proposed 
use, no license is finally effective unless and until full payment is received from you (either by publisher or by $\mathrm{CCC}$ ) as provided in CCC's Billing and Payment terms and conditions. If full payment is not received on a timely basis, then any license preliminarily granted shall be deemed automatically revoked and shall be void as if never granted. Further, in the event that you breach any of these terms and conditions or any of CCC's Billing and Payment terms and conditions, the license is automatically revoked and shall be void as if never granted. Use of materials as described in a revoked license, as well as any use of the materials beyond the scope of an unrevoked license, may constitute copyright infringement and publisher reserves the right to take any and all action to protect its copyright in the materials.

9. Warranties: Publisher makes no representations or warranties with respect to the licensed material.

10. Indemnity: You hereby indemnify and agree to hold harmless publisher and CCC, and their respective officers, directors, employees and agents, from and against any and all claims arising out of your use of the licensed material other than as specifically authorized pursuant to this license.

11. No Transfer of License: This license is personal to you and may not be sublicensed, assigned, or transferred by you to any other person without publisher's written permission.

12. No Amendment Except in Writing: This license may not be amended except in a writing signed by both parties (or, in the case of publisher, by CCC on publisher's behalf).

13. Objection to Contrary Terms: Publisher hereby objects to any terms contained in any purchase order, acknowledgment, check endorsement or other writing prepared by you, which terms are inconsistent with these terms and conditions or CCC's Billing and Payment terms and conditions. These terms and conditions, together with CCC's Billing and Payment terms and conditions (which are incorporated herein), comprise the entire agreement between you and publisher (and CCC) concerning this licensing transaction. In the event of any conflict between your obligations established by these terms and conditions and those established by CCC's Billing and Payment terms and conditions, these terms and conditions shall control.

14. Revocation: Elsevier or Copyright Clearance Center may deny the permissions described in this License at their sole discretion, for any reason or no reason, with a full refund payable to you. Notice of such denial will be made using the contact information provided by you. Failure to receive such notice will not alter or invalidate the denial. In no event will Elsevier or Copyright Clearance Center be responsible or liable for any costs, expenses or damage incurred by you as a result of a denial of your permission request, other than a refund of the amount(s) paid by you to Elsevier and/or Copyright Clearance Center for denied permissions.

\section{LIMITED LICENSE}

The following terms and conditions apply only to specific license types:

15. Translation: This permission is granted for non-exclusive world English rights only unless your license was granted for translation rights. If you licensed translation rights you may only translate this content into the languages you requested. A professional translator must perform all translations and reproduce the content word for word preserving the integrity of the article. If this license is to re-use 1 or 2 figures then permission is granted for non-exclusive world rights in all languages. 
16. Website: The following terms and conditions apply to electronic reserve and author websites:

Electronic reserve: If licensed material is to be posted to website, the web site is to be password-protected and made available only to bona fide students registered on a relevant course if:

This license was made in connection with a course,

This permission is granted for 1 year only. You may obtain a license for future website posting,

All content posted to the web site must maintain the copyright information line on the bottom of each image,

A hyper-text must be included to the Homepage of the journal from which you are licensing at http://www.sciencedirect.com/science/journal/xxxxx or the Elsevier homepage for books at http://www.elsevier.com, and

Central Storage: This license does not include permission for a scanned version of the material to be stored in a central repository such as that provided by Heron/XanEdu.

17. Author website for journals with the following additional clauses:

All content posted to the web site must maintain the copyright information line on the bottom of each image, and

he permission granted is limited to the personal version of your paper. You are not allowed to download and post the published electronic version of your article (whether PDF or HTML, proof or final version), nor may you scan the printed edition to create an electronic version,

A hyper-text must be included to the Homepage of the journal from which you are licensing at http://www.sciencedirect.com/science/journal/xxxxx , As part of our normal production process, you will receive an e-mail notice when your article appears on Elsevier's online service ScienceDirect (www.sciencedirect.com). That e-mail will include the article's Digital Object Identifier (DOI). This number provides the electronic link to the published article and should be included in the posting of your personal version. We ask that you wait until you receive this e-mail and have the DOI to do any posting.

Central Storage: This license does not include permission for a scanned version of the material to be stored in a central repository such as that provided by Heron/XanEdu.

18. Author website for books with the following additional clauses:

Authors are permitted to place a brief summary of their work online only.

A hyper-text must be included to the Elsevier homepage at http://www.elsevier.com

All content posted to the web site must maintain the copyright information line on the bottom of each image

You are not allowed to download and post the published electronic version of your chapter, nor may you scan the printed edition to create an electronic version.

Central Storage: This license does not include permission for a scanned version of the material to be stored in a central repository such as that provided by Heron/XanEdu.

19. Website (regular and for author): A hyper-text must be included to the Homepage of the journal from which you are licensing at

http://www.sciencedirect.com/science/journal/xxxxx. or for books to the Elsevier homepage at http://www.elsevier.com

20. Thesis/Dissertation: If your license is for use in a thesis/dissertation your thesis may be submitted to your institution in either print or electronic form. Should your thesis be 
published commercially, please reapply for permission. These requirements include permission for the Library and Archives of Canada to supply single copies, on demand, of the complete thesis and include permission for UMI to supply single copies, on demand, of the complete thesis. Should your thesis be published commercially, please reapply for permission.

\section{Other Conditions:}

\section{v1.6}

Gratis licenses (referencing $\$ 0$ in the Total field) are free. Please retain this printable license for your reference. No payment is required.

If you would like to pay for this license now, please remit this license along with your payment made payable to "COPYRIGHT CLEARANCE CENTER" otherwise you will be invoiced within $\mathbf{4 8}$ hours of the license date. Payment should be in the form of a check or money order referencing your account number and this invoice number RLNK10821555.

Once you receive your invoice for this order, you may pay your invoice by credit card. Please follow instructions provided at that time.

Make Payment To:

Copyright Clearance Center

Dept 001

P.O. Box 843006

Boston, MA 02284-3006

If you find copyrighted material related to this license will not be used and wish to cancel, please contact us referencing this license number 2477040825455 and noting the reason for cancellation.

Questions? customercare@copyright.com or +1-877-622-5543 (toll free in the US) or +1-978-646-2777. 